\title{
Calendar effects in daily aggregate employment creation and destruction in Spain
}

\author{
J. Ignacio Conde-Ruiz'1,2 Manu García ${ }^{1,2}$ • Luis A. Puch ${ }^{2,3}$. Jesús Ruiz ${ }^{2,3}$
}

Received: 22 September 2018 / Accepted: 21 February 2019 / Published online: 12 March 2019

(c) The Author(s) 2019

\begin{abstract}
In this paper, we discuss the time series properties of a novel daily series of aggregate employment creation and destruction as registered by the Social Security in Spain. We focus on the period of economic recovery after the 2012 Labour Market Reform. Our concern for high-frequency data is motivated by the recent upsurge of labour contracts of a very short duration, which seems to have exacerbated the spikes in employment flows over the calendar year. First, we identify calendar effects in job flows and single out the Monday effect: an overreaction in job creation at the beginning of the workweek. Then, we investigate the importance of calendar effects for aggregate employment dynamics. We find that the employment growth rate shows a systematic decrease by the end of each month, which is more pronounced during the second half of the year, and it intensifies as the economy moves further along the expansion period. Finally, we use the flow of contract records at the micro-level (several millions) to evaluate how the occupational structure determines employment spikes. Our findings indicate that short-term contracts are highly prevalent in occupations under stronger calendar effects. In particular, we show that temporary workers' contracts are the most important source of the Monday effect.
\end{abstract}

Keywords Employment flows · Fixed-term contracts · Calendar effects · Business cycle fluctuations $\cdot$ Sectoral composition $\cdot$ Regime shifts

JEL Classification J23 · E24 · C22

\footnotetext{
We thank Israel Arroyo, Floren Felgueroso, Marcel Jansen and Juan Jimeno for insightful discussions, as well as seminar participants at Fedea and Universidad de Málaga. We also thank two reviewers and the editor for their suggestions. Finally, we thank Fedea for the access to the SEPE data, and the Spanish Ministerio de Economía y Competitividad (Grant ECO2016-76818) and the Bank of Spain (Grant Excelencia 2016-17) for their financial support.
}

Extended author information available on the last page of the article 


\section{Introduction}

The Spanish labour market is characterized by high employment volatility and excessive labour turnover, among other undesirable outcomes. A new feature in recent employment flows, though, is the prevalence of contracts of a very short duration. Felgueroso et al. (2017) document that the number of short-term contracts has doubled during the last economic recovery as compared to the previous expansion, with an average duration that fell from about 3 months in 2006 to 50.6 days in 2016. This might be related to the widespread use of fixed-term contracts affecting temporary workers, but not only. ${ }^{1}$ A sustained hypothesis is that firms have learned to squeeze employment legislation to minimize costs associated with labour turnover or even take advantage of it. New digital technologies might also be allowing firms to improve the way they manage hiring and firing on a daily, or even hourly, basis. Besides the dual contractual structure, the administrative frictions, or the impact of digitalization, there are prevalent differences in technology across sectors that combined with seasonality of demand might have exacerbated employment spikes in recent times. For instance, Cahuc and Nevoux (2018) recently discuss how firms facing strong seasonal revenue fluctuations may have an incentive to make recurrent use of short-time work in France.

To further study these hypothesis, we need to organize the evidence on highfrequency movements in employment creation and destruction. To this end, this paper combines the daily aggregate employment data with the detailed register of new contracts (several millions) by occupations. Using these data, we show that substantial labour turnover occurs on a daily basis and intensifies at recurrent dates along the calendar year. Such a phenomenon has been discussed in the literature with lower frequency data. The classical reference to study the cyclical volatility of employment building from microeconomic evidence is Caballero et al. (1997). Wolfers (2005) studies the job flows caused by seasonal cycles, and Del Bono and Weber (2008) focus on labour demand differentials associated with seasonal employment fluctuations. Alternatively, here, we take advantage of a novel daily series of social security affiliations to precisely identify calendar effects on a daily basis, that is, employment creation and destruction depending on the day of the week or month. We further illustrate that the quantitative importance of calendar effects is related to the sectoral composition of the economy and business cycle fluctuations. The way this circumstance affects employment dynamics may be relevant for the design of policies aimed at forcing firms to internalize the social costs of their excessive lay-offs. In addition, the seasonality we describe makes the use of monthly data problematic to forecast labour market indicators or to nowcast activity.

Our data complements the micro-evidence. Daily social security registers collect information about start and end of all employment spells (both self-employed and employed workers). In 2016, over 26 million new registers (and 25.5 million deregisters) have been recorded in the Social Security database. This means that the number

\footnotetext{
${ }^{1}$ Dolado et al. (2002), Bentolila et al. $(2008,2012)$ and Costain et al. (2010) among others discuss the institutional factors that give rise to the high incidence of temporary employment and a dual labour market in Spain. For labour demand-related factors see, for instance, Benito and Hernando (2008). Blanchard (2004), inspired by Blanchard and Tirole (2003), soon proposed a single open-ended contract for new hires to address this issue.
} 
of new registers every year can be up to 1.5 times higher than the stock of workers affiliated to the Social Security. The numbers are also astonishing on daily data: On average, over 100,000 new registers and about 100,000 deregisters were presented per day. In addition, we use the contract records at SEPE (Servicio Público de Empleo Estatal/Official Employment Information Administration) of the Ministerio de Trabajo y Seguridad Social (MESS, Spanish Ministry of Employment and Social Security) to track the sectoral composition of employment on a daily basis. ${ }^{2}$ The reason is that affiliation data by sector or occupation are unavailable. One drawback about using contract records is that it excludes self-employed workers. In any case, we contrast the time series properties of employment creation with those of new contracts. The main finding is that the number of records of self-employed goes up when the number of new contracts shrinks. We then arrange about 100 million new contracts from January 2011 to August 2017, across the different occupations in the MESS classification at two digits, to study calendar effects from the sectoral composition of the economy.

As we shall see, casual observation suggests strong calendar effects by the beginning and the end of the week, as well as by the beginning and the end of the month. We identify the strength of these calendar effects, how they change over time, and the way in which they are different for the flows of employment creation and destruction, and the number of new contracts. In the first part of the paper, we analyse the calendar effects on aggregate job flows over the period 2012-2017 using time series methodology. The main finding is that most of the episodic variation in the series comes from creation and destruction of very short term contracts. We identify Mondays and Fridays as key days in the process of job creation and destruction by firms. However, the importance of what we call the "Monday effect" clearly dominates, both for the start and the end of employment spells. Also, the interaction of the effect at the beginning and end of the week with the beginning and end of the month is key, and we find evidence of a rollover of contracts every month. Thus, we investigate an end-of-month effect on net employment growth, and we find asymmetry between two states of employment: a "normal" state most of the time and a state of low growth by the end of every month. The regime shifts we measure (Markov-switching model) are more intense during the second part of the year, and they are intensified the more the economy moves further along the expansion period. We conclude that our average results are the convolution of calendar effects at different months and stages of the expansion period.

Using the universe of contracts registered in Spain, we next explore the strength and variability of calendar effects. The goal is to identify occupations with high turnover towards which the labour market policy should devote special attention, either in the form of active labour market policies or in terms of labour inspection. Therefore, we quantify the contribution of the occupational structure to the Monday and Friday effects. We find that occupations with stronger Monday effects exhibit higher temporary rates and more contracts per new employee, i.e. a higher prevalence of short-term contracts. Our analysis further identifies the relative importance of several sources of

\footnotetext{
2 SEPE allowed us to use its statistics of contracts on the basis of a research agreement with Fedea. We are very grateful for the access to this disaggregated data. Unfortunately, we can only approximate the disaggregation of job creation in Social Security by the new contracts registered at SEPE, as Social Security offers no access to their disaggregated employment creation and destruction data.
} 
calendar effects for new contracts. The finding here is that more than two-thirds of the direct Monday effect can be attributed to the evolution of new contracts for temporary workers.

Several authors have discussed the micro-evidence on the determinants of shortterm work in Spain. A strand of the literature has established that temporary contracts fail to act as stepping stones to regular employment for many labour market entrants, as discussed by Amuedo-Dorantes (2000), García-Pérez and Muñoz-Bullón (2011), Arranz and García-Serrano (2014) and Bonhomme and Hospido (2017), among others. Nagore and van Soest (2017) and Bentolila et al. (2017) show that fixed-term contracts help to reduce the risk of long-term unemployment, but at the same time, they drive huge inflows into unemployment. Güell and Petrongolo (2007) focus on the institutional arrangement and find a pronounced spike in the conversion of fixed term into permanent contracts at the legal limit. Felgueroso et al. (2017) further discuss the way in which shorter contracts and frequent unemployment spells affect the transitions from temporary to permanent employment. In line with these authors, we investigate the prevalence of short-duration contracts and labour turnover. However, we stress that the recent upsurge of short-term contracts seems to have exacerbated calendar effects with varying intensity across time and occupations. We focus on the period after the 2012 labour reform, yet the traditional factors behind employment volatility in the Spanish labour market persist. ${ }^{3}$ Methodologically, the focus on deterministic effects is the novelty for the daily movements under study, in contrast to conditional variance as it is the case with the time-varying volatility observed in financial daily data. ${ }^{4}$ Consequently, the time series methods we present should be of interest for related applications with daily macroeconomic data.

The organization of the paper is as follows. Section 2 describes the social security and contract records data and introduces the importance of calendar effects. Section 3 analyses the deterministic components associated with the employment creation and destruction calendar in Spain. Section 4 explores the consequences of the calendar effects identified on aggregate employment dynamics and implements a Markov-switching model for the employment growth rate. Section 5 explores the cross-sectional aspect, that is, the role of the sectoral composition of contracts to account for the variability associated with the identified calendar effects. Section 6 concludes.

\footnotetext{
3 The 2012 reform targeted labour costs to support "internal devaluation" (i.e. encourage wage moderation). At the same time, the reform promoted internal flexibility, so the firms could use other ways to adjust employment. It is too soon to analyse the effects of this reform approved on 10th of February 2012 by the Minister Council. Recent work shows that the reform has had some impact on wage moderation, but it has hardly affected the duality [cf. Izquierdo et al. (2013) and García-Pérez and Mestres-Domènech (2017)].

4 Calendar effects have been extensively discussed in finance (Berument and Kiymaz 2001) to analyse market volatility along the week. Clearly though, there is no market to trade claims on job creation and destruction to link to finance. Also, the availability of daily data brings about questions relevant for consumption and retail sales analysis, forecasting, or macroeconomics [cf. Soares-Esteves and Rodrigues (2010) and Verbaan et al. (2017)].
} 


\section{Data}

We use two administrative datasets at the daily frequency. First, we use the register of affiliations in Social Security. This includes the figures for aggregate employment creation and destruction in the Spanish economy on a daily basis for employed and self-employed workers. The homogeneous sample under study covers the period 20122017. Secondly, given that affiliation data by sector or occupation are unavailable, we use the micro-data on new contracts registered by the Spanish Ministry of Employment and Social Security through the SISPE (Sistema de Información de los Servicios Públicos de Empleo/Official Register of Employment). Contracts are coded at SISPE with an identifier for the different occupations and the starting dates of all employment spells. Using these dates, we aggregate the number of contracts to compare it with the daily employment creation data. It is worth noting, however, that affiliations are only registered on weekdays. Thus, to make the figures by occupations comparable with the affiliations data, we have assigned the contracts registered during the weekend or a bank holiday to the first subsequent weekday. A description of the sources and methods used in our data construction is given in "Appendix".

Both datasets have advantages and disadvantages. A shortcoming of the register of contracts is that it excludes self-employed workers. Consequently, the identification of calendar effects is of particular importance for the social security affiliation data. This comes at the cost of the distortion associated with the fact that the register of affiliations is closed during the weekend and bank holidays. Such a distortion is relevant for what we shall call the Monday effect, so we distinguish Mondays from the beginning of the week. More in general, it is common in the literature to consider calendar differences along (i) the day of the week, (ii) the month of the year, and (iii) holidays, as we do. In addition, we see that while the intra-month profile is unsubstantial to the duration of employment spells, it is key to focusing on the coincidence of the beginning and end of the week and the month. Next, we provide a preliminary description of the data and the associated calendar effects. The time variation and sectoral differences made apparent by this description motivate a subsequent in-depth look at measurement afterwards.

\subsection{The affiliation data}

At first sight, the affiliation data exhibit clear yearly and monthly patterns. Figure 1a depicts the evolution of the daily register of Social Security affiliations in Spain from February 2012. The number of affiliations reached a minimum at the beginning of 2013 with 16.1 million affiliations. After that, and starting at 2014, the picture shows a clear annual pattern of growth along a rising trend. The pattern is that every year along the expansion, the number of affiliations rises in the first part of the year, but flattens over the second part of the year. Following this annual pattern, the number of affiliates has increased by $13 \%$, to reach 18.3 million affiliates (our last month), at a $3.5 \%$ annual growth (0.6 million new affiliates per year).

Figure $1 \mathrm{~b}$ compares the annual pattern across the years. With the exception of the series for 2012 depicted in the middle of the graph, the data series from 2013 to 2017 are ordered upwards showing the increase in affiliations (expansion) and always exhibiting 


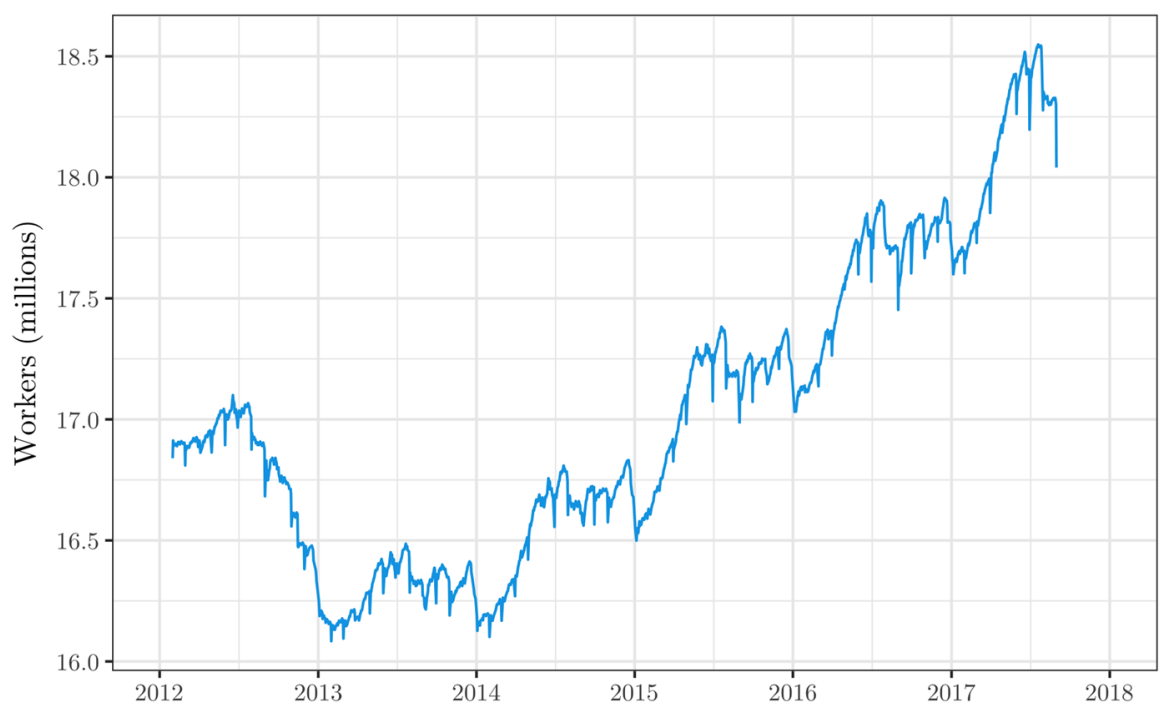

(a) whole sample

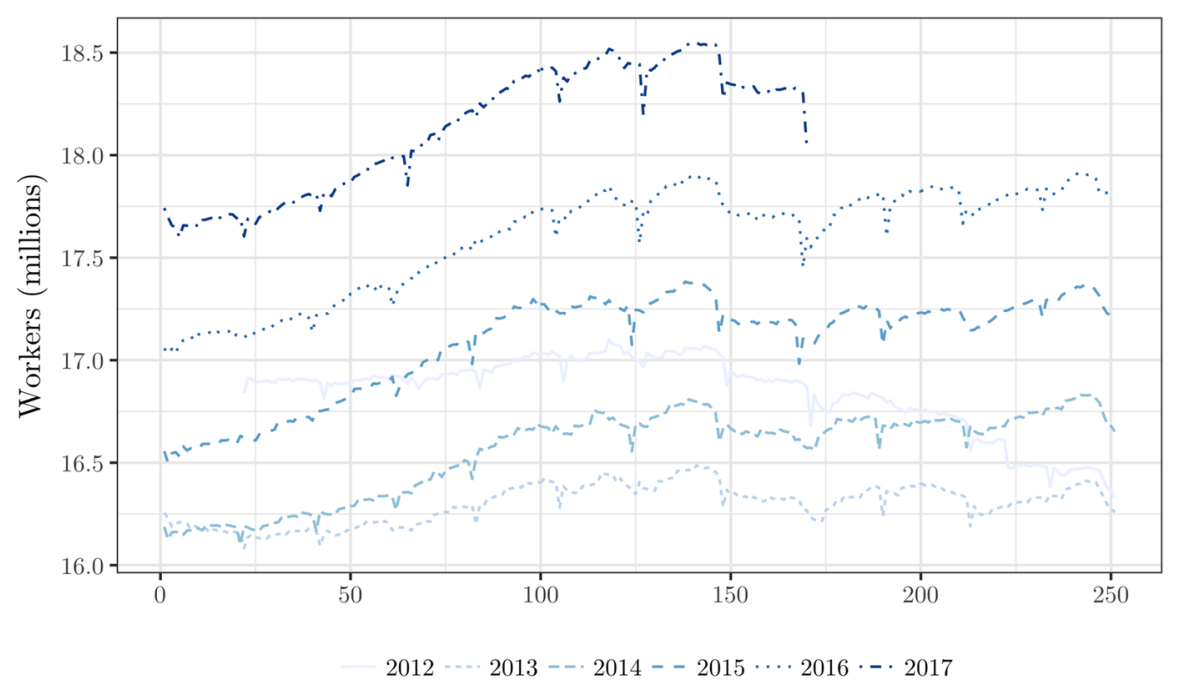

(b) per years

Fig. 1 Daily social security affiliates, 02/01/12-08/31/17

a clear "first up, then flat" pattern (within a year cycle). In addition, recurrent fluctuations are apparent across months, with substantial drops particularly by the end of some months. The observed ladder-shape pattern in affiliation growth that we observe is highly related to seasonal economic activities. Figure 2a shows the affiliation data on a monthly basis together with a series subtracting accommodation and restaurant services activities from it. Clearly, affiliation in the food and accommodation sector first goes up and then down along the expansion. As illustrated in Fig. 2b, this brings 


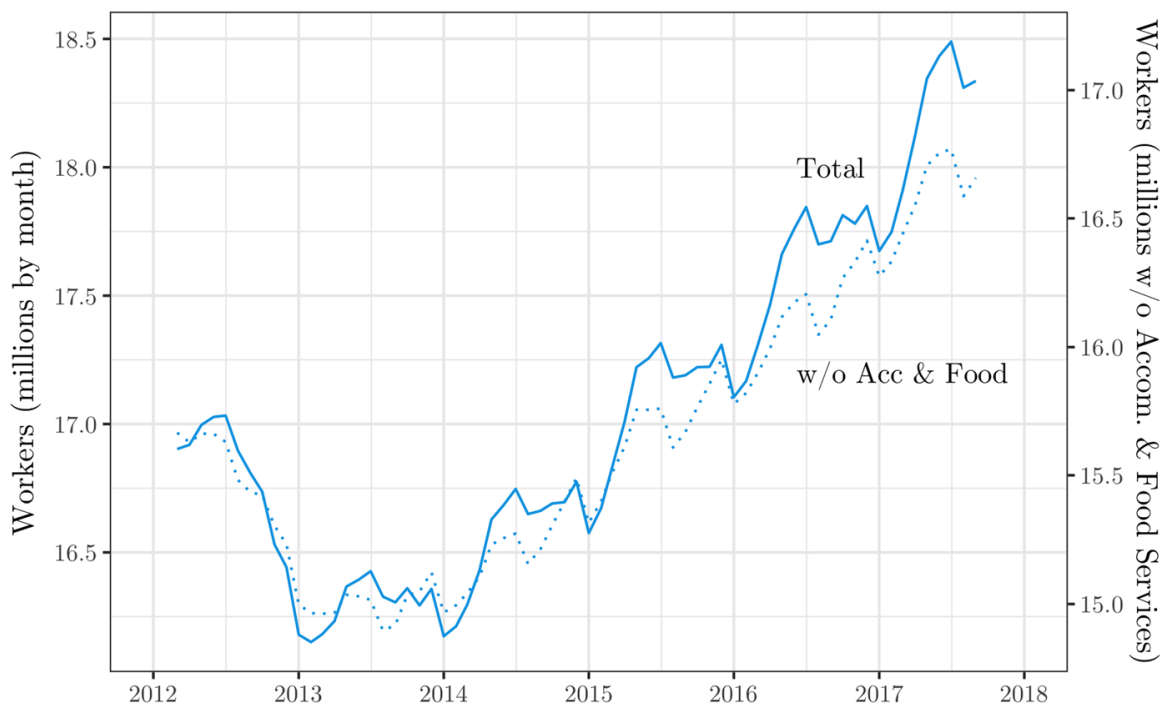

(a) Soc Sec affiliates (monthly averages): aggregate and excluded restaurant and accommodation services

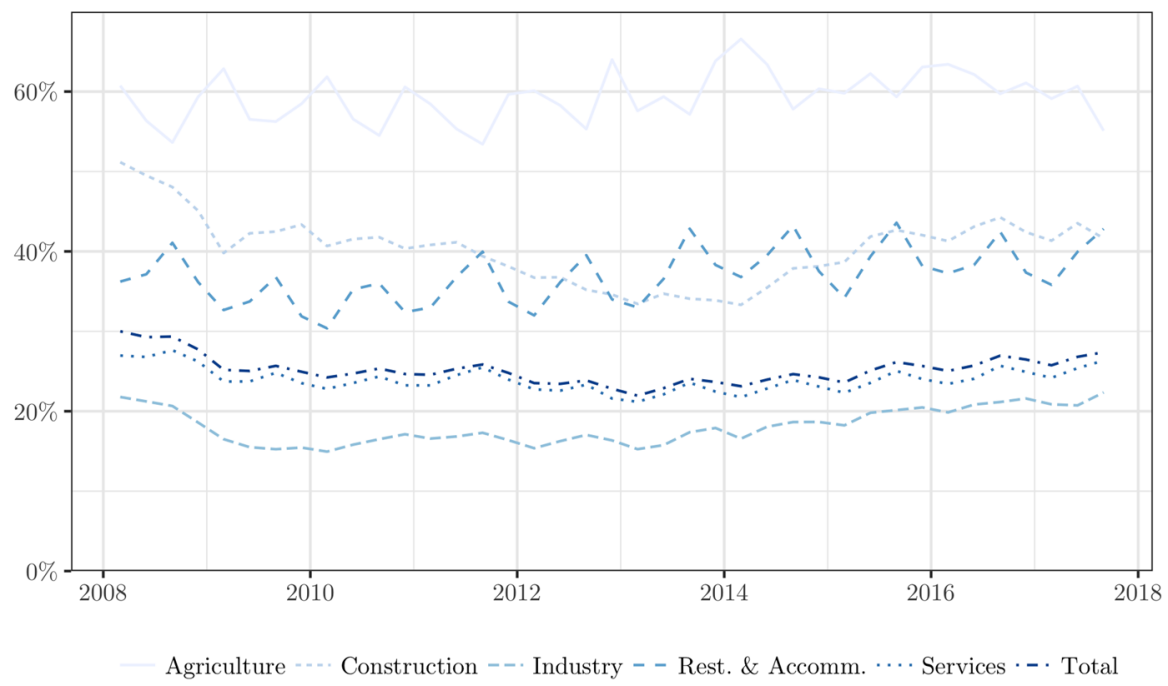

(b) Temporary employment rate (fixed-term $i /$ total sector $i$ ): aggregate and selected sectors. Source EPA

Fig. 2 Employment measures in various sectoral activities

about the issue of the sectoral composition of the economy and its interaction with the share of temporary workers in some specific activities.

\subsection{The flow data: creation, destruction, and new contracts}

Figure 3 summarizes the path of employment creation and destruction across the 6 years in the sample. For comparison purposes, we include the aggregate number of 


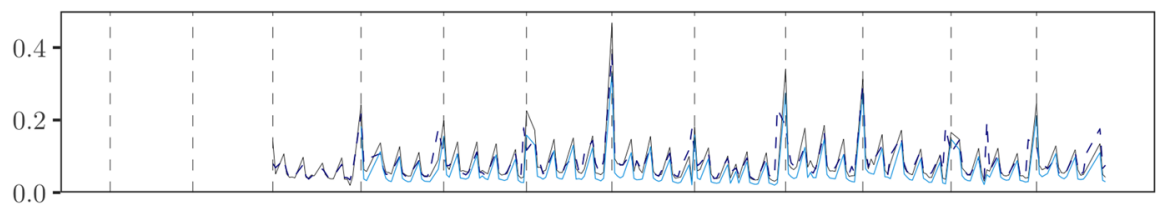

(a) 2012

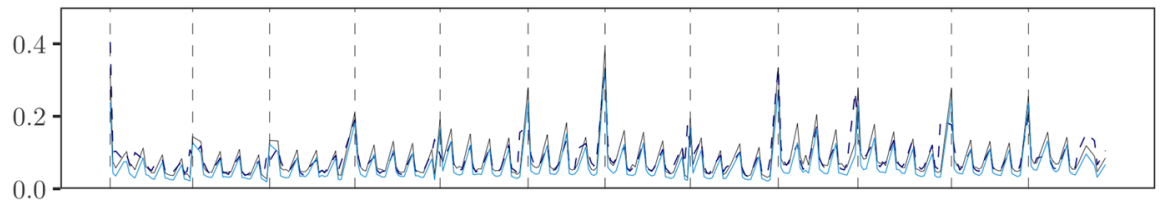

(b) 2013

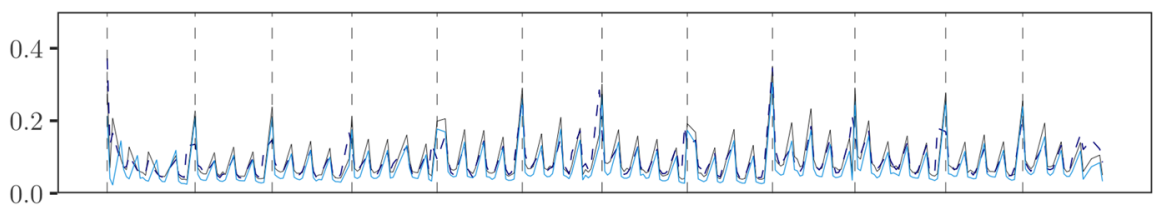

(c) 2014

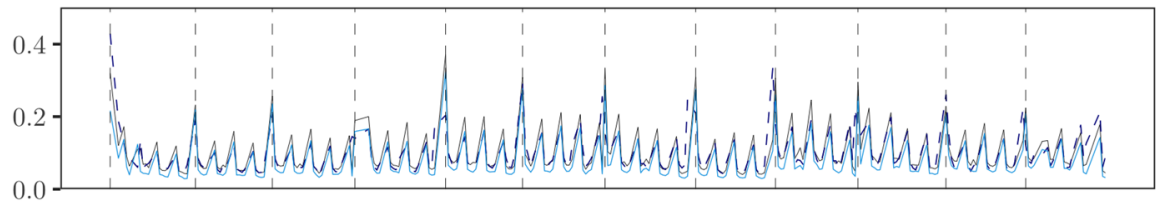

(d) 2015

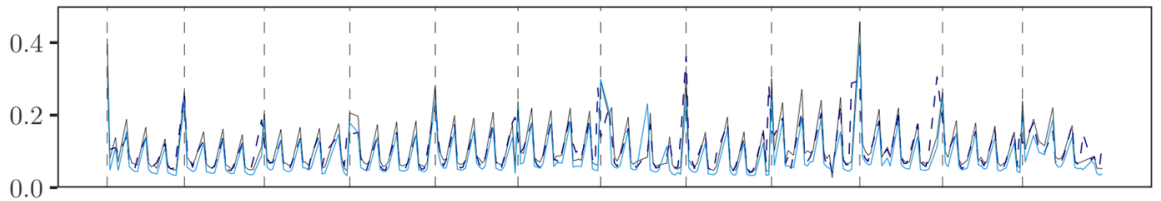

(e) 2016

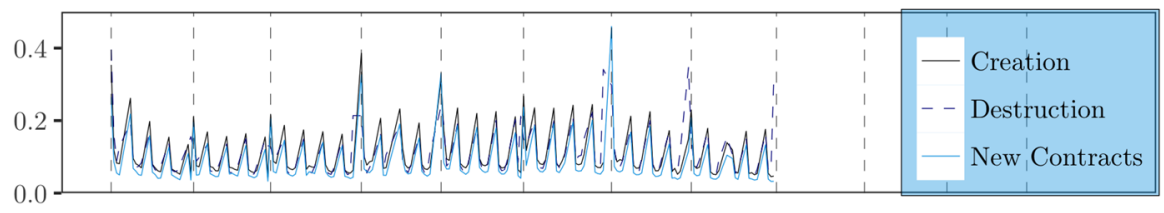

(f) 2017

Fig. 3 Creation and destruction, together with new contracts (all in millions) over the years (vertical lines go first workday each month) 
new contracts. All figures are in millions. The behaviour of the series deserves various considerations. The bigger spike corresponds to the beginning of every week, normally a Monday except on a holiday, so we will refer to this spike as a Monday effect. A spike is also present at the end of the week. We will refer to this as a Friday effect. The Friday effect is less important than the Monday effect. Moreover, the Monday effect is one in which both creation and destruction of jobs coincide, except when the first day of the month is other than a Monday. Actually, the spikes are bigger if the beginning of the week coincides with the beginning of the month, and correspondingly, if the end of the week coincides with the end of the month. ${ }^{5}$ Also, the spikes are typically larger during the summer period, and this effect turns out to be stronger as the economy moves further along the expansion period of the business cycle. A detailed explanation of the data is given in "Appendices A and B".

We quantify the importance of these spikes with regression techniques, and we elaborate on the economics behind them. Clearly, individuals and firms coordinate their activities or decisions according to the calendar. For instance, individuals receive the wage pay at the end of the month, or firms start a new campaign at the beginning of a year, among others. Thus, it is not surprising to find calendar regularities in our daily series. The question is how the daily movements relate to monthly averages in a way that varies along the calendar year and over the business cycle. This relationship seems to be driven by hiring and firing practices and administrative frictions (including distortions in the register), differences in technology and seasonality in demand across sectors, and the prevalence of temporary employment. Our goal is to measure these sources of calendar effects.

\section{Calendar effects in daily employment creation and destruction}

In Sect. 2.2, we described the daily patterns of employment creation and destruction, as well as the related evolution of new contracts. In particular, Fig. 3 above illustrates that employment flows concentrate on Monday and Friday, except when these days are other than the beginning or the end of the month, respectively. At the same time, creation and destruction are reinforced when the beginning or end of the week coincides with the beginning or end of the month. Aggregate new contracts and employment creation move alike except for the smoothing associated with movements in the selfemployed, whose figures go up when job creation moderates. Next, we identify the extent to which the measurement of calendar effects goes beyond visual inspection.

\subsection{A time series model for daily employment flows}

We specify a deterministic and autoregressive time series model for all our flow variables of interest,

\footnotetext{
5 "Appendix A" reports this effect when the end of the month coincides with the end of the week (the highest spike on employment destruction) and when the start of the week coincides with the start of the month (the highest spike on employment creation). Notice that the employment spells destroyed or created each month represent approximately $10 \%$ of total affiliates, a monthly rate akin to the annual rates for the USA. (see also Tables 6 and 7 in "Appendix").
} 


$$
\begin{aligned}
\log \left(\text { flow }_{t}\right)= & \beta_{\mathrm{M}} x_{t}^{\mathrm{M}}+\beta_{\mathrm{F}} x_{t}^{\mathrm{F}}+\beta_{\mathrm{R}}\left(1-x_{t}^{\mathrm{M}}-x_{t}^{\mathrm{F}}\right) \\
& +\sum_{j=1}^{12} \gamma_{j} x_{j, t}^{\mathrm{BM}}+\sum_{j=1}^{12} \eta_{j} x_{j, t}^{\mathrm{EM}}+\sum_{j=1}^{\mathrm{S}} \varphi_{j} x_{j, t}^{\mathrm{Seas}}+\sum_{j=1}^{12} \gamma_{j}^{\prime} x_{j, t}^{\mathrm{BM}} x_{t}^{\mathrm{M}} \\
& +\sum_{j=1}^{12} \gamma_{j}^{\prime \prime} x_{j, t}^{\mathrm{BM}} x_{t}^{\mathrm{F}}+\sum_{j=1}^{12} \eta_{j}^{\prime} x_{j, t}^{\mathrm{EM}} x_{t}^{\mathrm{M}}+\sum_{j=1}^{12} \eta_{j}^{\prime \prime} x_{j, t}^{\mathrm{EM}} x_{t}^{\mathrm{F}}+m_{t},
\end{aligned}
$$

where the (log) "flow" variable can be job creation, job destruction, or the register of contracts, and the regressors $x$ are a set of dummy variables that cover all calendar effects (deterministic part). ${ }^{6}$ Dummies are labelled M(onday), F(riday), B(eginning of) M(onth), E(nd of) M(onth), and Seas(onal). Finally, the (stochastic) error term $m_{t}$ is allowed to follow an ARMA model

$$
m_{t}=\frac{\sum_{j=1}^{J} \theta_{j} B^{j}}{\left(1-\sum_{k=1}^{K} \varphi_{k} B^{k}\right)} \varepsilon_{t},
$$

with $B^{j, k}$ being the lag operator of order $j$ or $k$ correspondingly, and $\varepsilon_{t} \sim N\left(0, \sigma_{\varepsilon}^{2}\right)$.

We specify calendar effects comprehensively to cover daily and monthly effects and their interactions. It turns out, however, that a compact representation comes to settle quickly with the descriptive evidence discussed above, in the sense that some of the calendar effects specified are not relevant. For instance, only the Monday and (mildly) Friday effects are significantly different from the rest of the workweek. Thus, to cover the direct daily effects, we next specify a constant in Eq. (3.1), together with the Monday and Friday dummies. Likewise, only the effect of some months is significantly different from the rest and, in those cases, significance is associated with seasonal economic activity. Therefore, we incorporate a set of seasonal dummies, $x^{\text {Seas }}$, for the monthly effects. These dummies account for economic activity during (i) the summer season (an April to July dummy denoted Sun), (ii) the agricultural season (a September-October dummy Agri, related to the harvesting of wine grapes), and (iii) the Christmas period (a December dummy Xmas). Although these are the most salient cases of combined calendar effects, we discuss some others below.

Table 1 summarizes our preferred specification among several possibly equivalent alternatives. The left panel contains calendar time dummies and autoregressive elements, whereas the right panel also includes the aforementioned dummies for the seasonal economic activity in the Spanish economy. The table consists of three blocks of variables. Figure $4 \mathrm{a}-\mathrm{f}$ summarizes the middle block, which refers to the differential daily effect at the beginning and the end of the month for each and every month. The first block of variables, in its turn, includes the main daily dummy variables, while the last block includes the seasonal dummies and the autoregressive components. Summary statistics may be seen at the end of the last block. The adjusted $R^{2}$ for

\footnotetext{
6 That is, the time series model is just $\log \left(\right.$ flow $\left._{t}\right)=\beta_{0}+G\left(\xi_{t}^{n} ; \beta\right)+m_{t}$, where $\xi_{t}$ is a set of dummy variables up to order $n$ for calendar effects, so that $\beta$ is a $(N \times 1)$ vector of regression coefficients, and the error term is $m_{t}$. Note parametric dummies in Eq. (3.1) are denoted $\mathrm{x}$.
} 


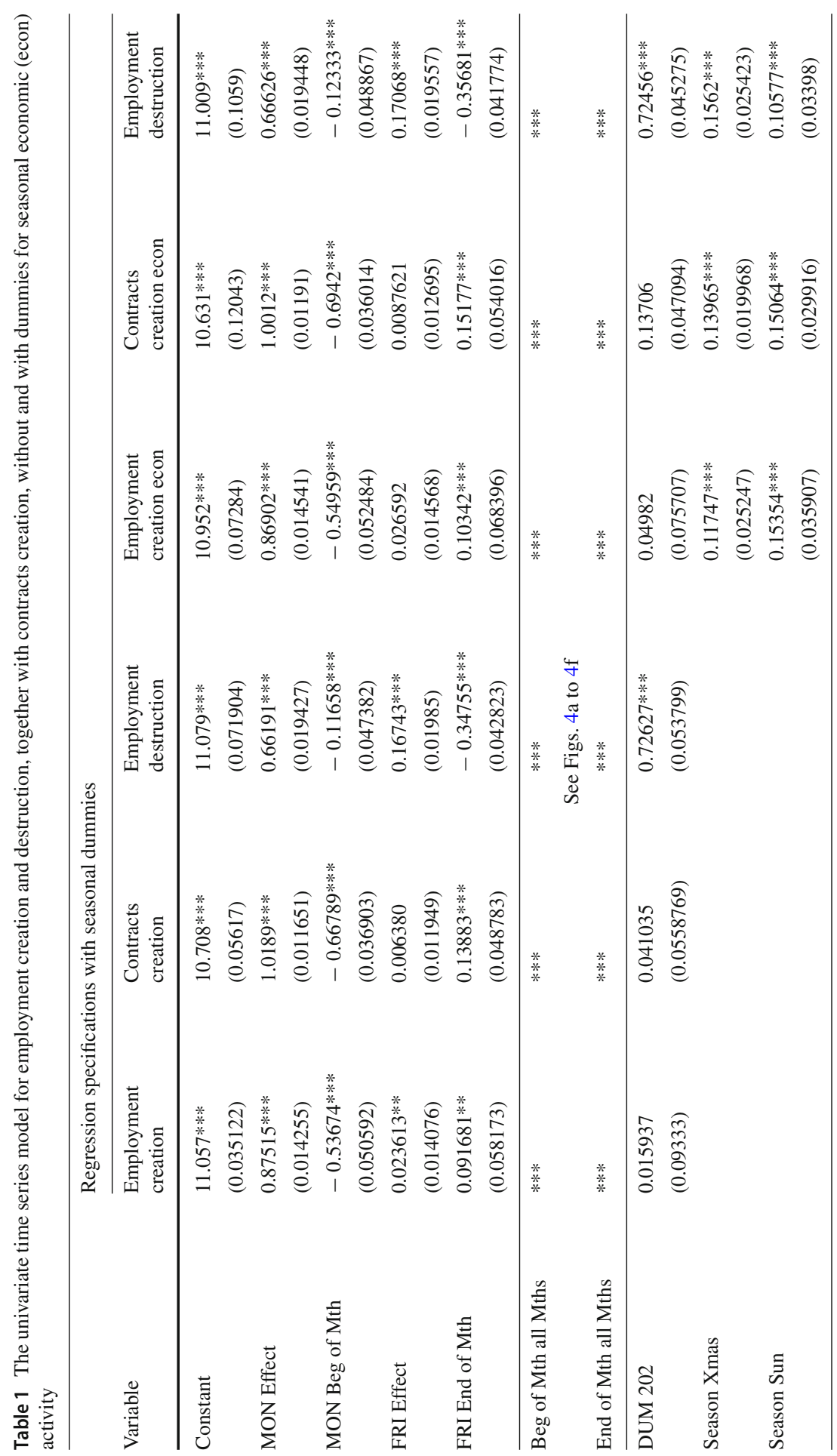




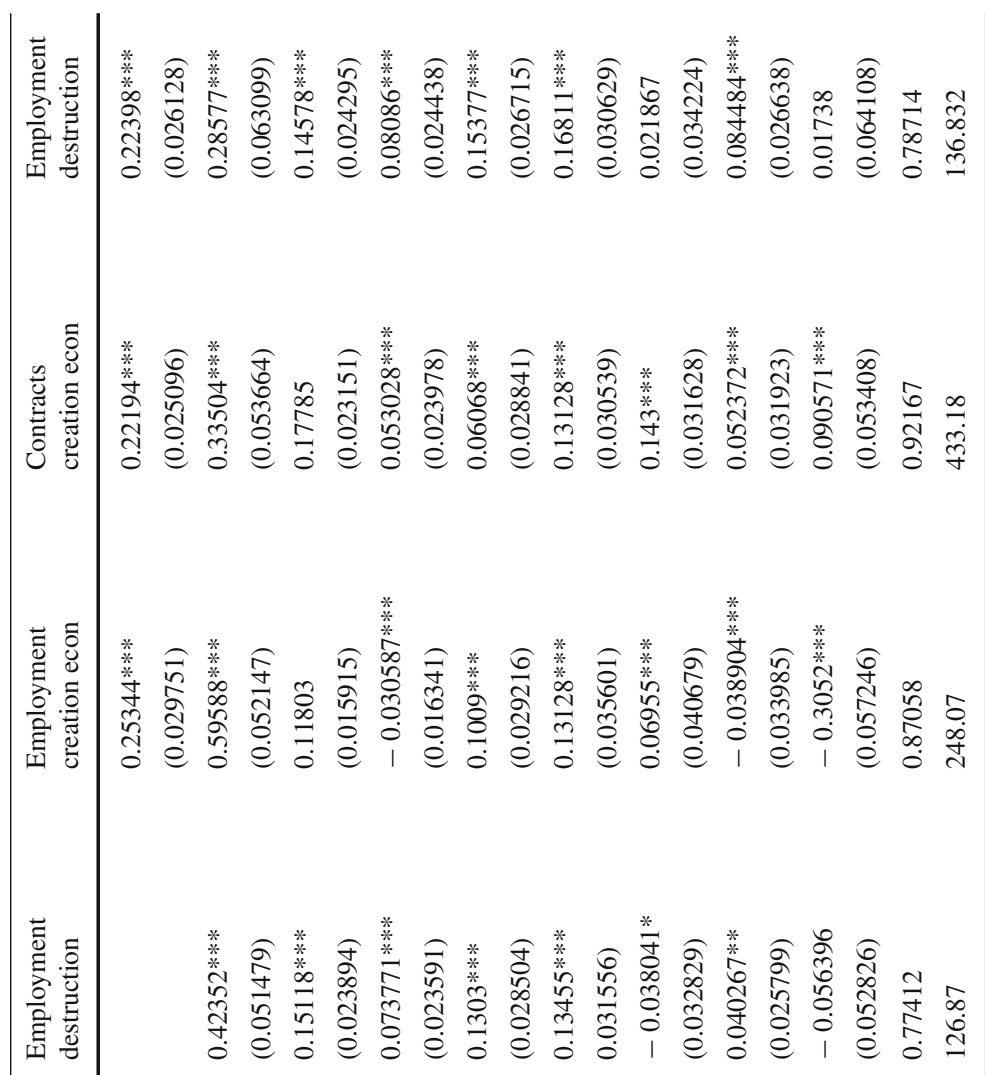

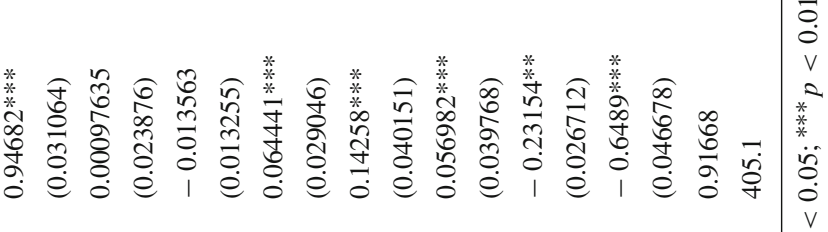

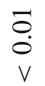

苛

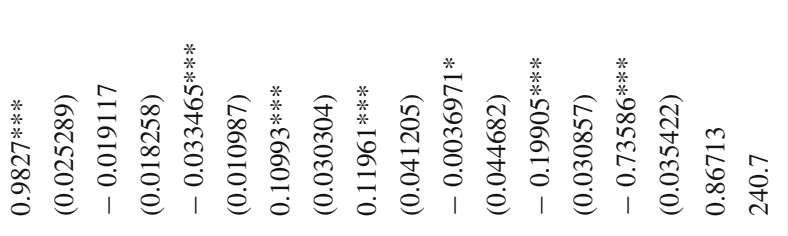




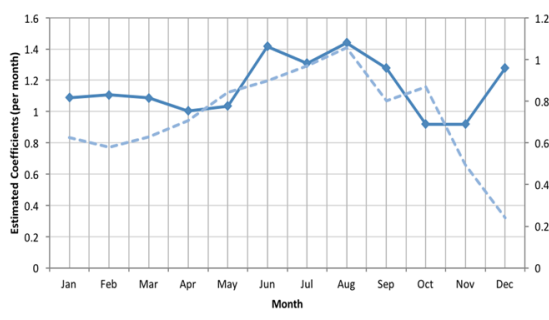

(a) Beg./End of Month Crea/Dest

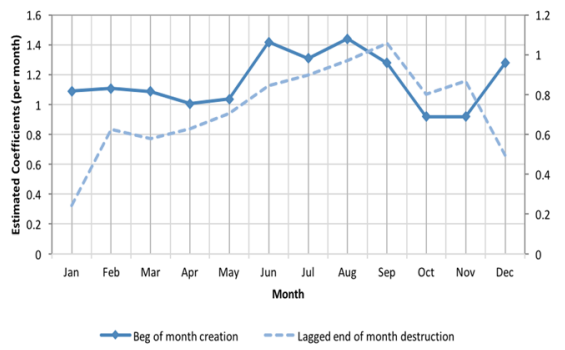

(c) Beg./Lagged End of Month Crea/Dest

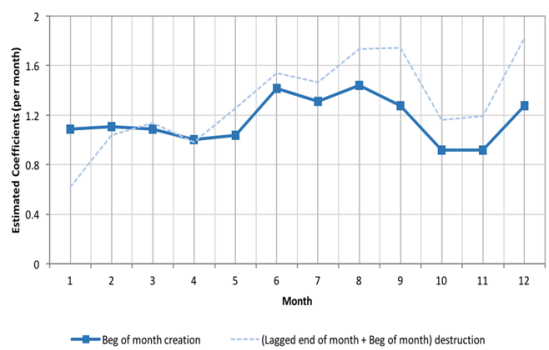

(e) (Lagged End + Beg.) $/$ Beg. of Month Crea/Dest

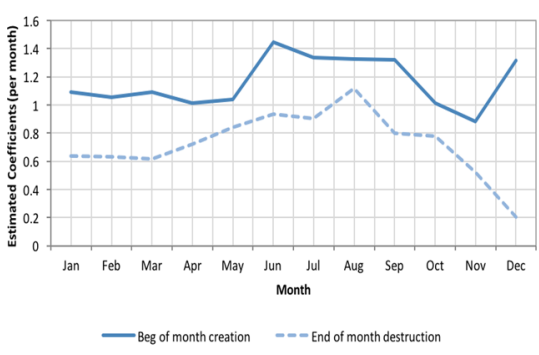

(b) Beg./End of Mth Crea/Dest with Economic Vars.

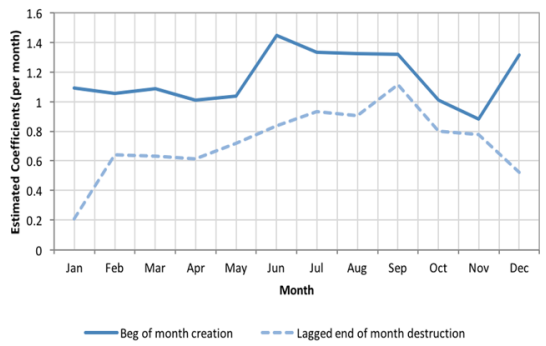

(d) Beg./Lagged End of Mth Crea/Dest w/ Econ. Vars.

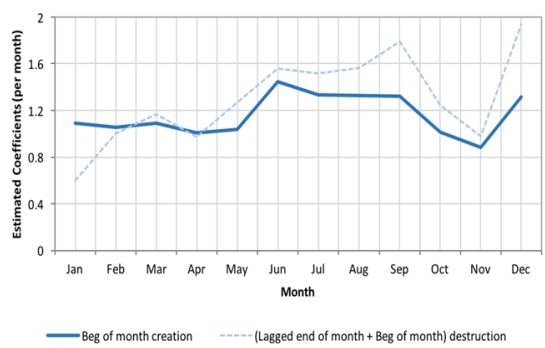

(f) (Lagged End + Beg.)/Beg. of Mth Crea/Dest w/ Econ.Vars.

Fig. 4 Estimated Beg/End of month patterns in job creation and destruction

the log of employment creation specification is above 0.86 , whereas it is above 0.77 for employment destruction, with a small contribution of economic effects (seasonal dummies) to the regression fit. We do not include intra-month profiles because the autoregressive estimates in the last block show that the pattern of persistence is strong at lags 1 (a day), and 19, 20, and 22 (a month) but not for lags in between. Lags 5 (1 week) and 10 (2 weeks) are significant only for the log of employment destruction. Beyond the finding at lag 5 and 10, there is an event specific dummy (DUM 202) that is significant only for employment destruction: This captures job destruction the day after the general strike on 14 November 2012. Finally, controlling the regression for the economic activity dummies in general amplifies the calendar effects and interacts with the beginning and end of month effects as we will see in the section below. 


\subsection{Key calendar effects}

The first key calendar result is the importance of the Monday effect both in employment creation and destruction. Note that the Monday effect comes in the regression in three parts: (i) in a dummy taking value one every Monday, that is, the direct MON(day) Effect, (ii) in a different dummy taking value one when the beginning of a month is a Monday (MON Beg of Mth), and (iii) in other dummies taking value one at the beginning of every month (Beg of Mth) or the end of every month (End of Mth), whenever any of them is a Monday. Thus, for instance, the negative sign in the coefficient of the dummy MON Beg of Mth in Table 1 is interpreted through this composition first and based on the fact that all months are not alike as discussed below. ${ }^{7}$ Likewise, the Friday effect combines the effect of the set of dummies for (i) Friday, (ii) Friday and end of month, and (iii) beginning or end of every month if Friday. As expected, the direct Monday effect is more important for creation than it is for destruction, but strikingly the effect is not that different. Correspondingly, the Friday effect is more important for destruction than it is for creation indeed, but overall, as a calendar effect, it turns out to be a much less important than the Monday effect.

While the detailed estimates for the different calendar effects are informative, one may wonder on the average Monday and Friday effects. We compute average effects as the weighted sum of all the individual effects estimated, the weights being the frequency at each dummy variable of the corresponding calendar event (that is, the probability mass function). For instance, whenever a dummy variable is equal to 1 on a Monday, a Monday effect adds up through the corresponding estimated coefficient. Coefficients are added up weighted by the fraction of Mondays at each dummy variable over the sum of Mondays at all calendar events (that is, the sum over all dummy variables). With this procedure, we compute an average Monday effect, say $\bar{\beta}_{\mathrm{M}}$, on employment creation, of 0.955 . This is nearly $1 \%$ point above the direct Monday effect, $\beta_{\mathrm{M}}$. Precisely, $\left(\bar{\beta}_{\mathrm{M}}-\beta_{\mathrm{M}}\right) / \beta_{0}=0.78 \%$, with $\beta_{0}$ being the constant of employment creation conditional on seasonal economic activity. Notice that the direct Monday effect was already $8 \%$ above the average weekday effect. Likewise, we compute an average Friday effect on employment destruction of 0.2674 . This is $0.88 \%$ above the direct Friday effect. We interpret that the Monday and Friday effects are mostly driven by factors common to all sectors rather than monthly or seasonal economic factors. Below we explore the contribution of the different sources of calendar effects across sectors.

Finally, as shown in Table 1, calendar effects are stronger for the flow of new contracts than for the flow of total employment creation (of wage-employed and self-employed workers), with the only exception of the direct Friday effect. This is consistent with the finding in Carrasco (1999) that self-employment provides an escape to precarious workers, making them more attractive in terms of the labour cost borne by the firms. The evidence she obtains for Spain reinforces the finding that the self-employed are poor workers and misfit for paid work, a labour profile common among workers under fixed-term contracts. Furthermore, the Friday effect

\footnotetext{
7 Actually, the coefficient of the dummy MON Beg of Mth is positive in the regression that excludes a beginning of month dummy for every month.
} 
difference between employment creation and new contracts suggests a weekly margin more associated with the self-employed, whereas the monthly margin is more related to contracts. Notice that the effect of paradoxical combinations Friday-and-beginning of month or Monday-and-end of month is nonsignificant. This reinforces the role of the coincidence of weekly and monthly starts and ends for employment dynamics in the short-term contracts environment of the Spanish economy. The finding that calendar effects are amplified once we control for seasonal economic activity suggests important episodic movements in non- seasonal occupations too.

\subsection{Calendar effects and the rollover of contracts}

There is a second set of results on calendar effects (under rows Beg and End of Mth all Mths in Table 1) that are related to the rollover of contracts. The beginning of each month is the starting date for the contracts with an employment duration of a month, and the end of each month is the termination date for those contracts. Therefore, we should expect a spike on the employment creation at the beginning of the month and a spike on employment destruction at the end of the month. Thus, we control in the regressions for the daily effect of the start or end of the month, and we do so with a different dummy variable for each case (beginning or end) every month. Then, we proceed with a detailed analysis of the yearly cycle dimension of the estimated coefficients in Fig. 4. We restrict this to employment creation (and destruction) since the monthly calendar effects in contracts are not significantly different.

Figure 4a gathers the estimates (two scales) for the responses in creation at the beginning of the month and destruction at the end of the month. This comparison is therefore within the month: the effect on creation by the beginning of the month and on destruction by the end of the same month. Notice from Figure $4 \mathrm{~b}$ that conditional on seasonal dummies, the estimates are not that different in size, and actually, the gap in the figure should give a measure of average net employment creation along the year. This gap widens at the beginning of the year and narrows during the summer, with the beginning of June spike on creation nearly compensated by the spike in destruction at the end of August. The main calendar discrepancy occurs with the fall in job destruction by the end of November and December, linked to the Christmas season. ${ }^{8}$

This finding motivates the concatenation of creation and destruction described in Fig. $4 \mathrm{c}$ and d, that summarizes the response in creation at the beginning of the month together with the response of destruction at the end of the previous month. As the year moves on, greater destruction at the end of the month corresponds to creation beginning the following month, except for the months of January versus December. The last panel, Fig. 4e and f, puts together the destruction estimates: lagged and contemporaneous destruction, with every beginning of month creation. The coefficients move together and often exactly cancel out. These findings point to a neat monthly effect on employment growth, where the average effect described is a combination of

\footnotetext{
8 Note the effect is unmitigated once we include the Christmas dummy in the regression, as depicted in Fig. 4b. This is not surprising because the holidays effect and the activity effect during Christmas nearly compensate each other in the aggregate, as shown below.
} 
the monthly effect over different years. Next, we show how this monthly effect varies over the business cycle.

\section{Aggregate employment dynamics over the calendar year}

In this section, we explore the transmission of calendar effects to the stock of Social Security affiliates. We have seen that affiliation data show a systematic fall by the end of each month that relates both to the destruction of part of the jobs created during that month and to the rollover of contracts. To evaluate this monthly effect, we explore the unexpected variation in net employment growth, once we control for deterministic and autocorrelated elements.

\subsection{A time series model with regime switching for employment growth}

Let us consider the number of affiliations in Social Security, affi $t$, on a daily basis. In line with the discussion in Sect. 3, we now specify an univariate time series model in first-differences,

$$
\nabla \log \left(\mathrm{affi}_{t}\right)=F\left(\nabla \xi_{t}^{l} ; \beta\right)+a_{t}
$$

with $\nabla$ being the first-difference operator, $\xi_{t}$ a set of dummy variables up to order $l$ in first-differences (so $l \neq n$ above), and the error term $a_{t}$ is allowed to follow an ARMA model

$$
a_{t}=\frac{1+\sum_{j=1}^{J} \theta_{j} B^{j}}{\left(1-\sum_{k=1}^{K} \varphi_{k} B^{k}\right)} \varepsilon_{t},
$$

with $B^{j, k}$ being the lag operator of order $j, k$ and $\varepsilon_{t} \sim N\left(0, \sigma_{\varepsilon}^{2}\right)$. Notice that under linear $F(\cdot)$, the specification in (4.1) is equivalent to a specification in levels such as

$$
\log \left(\operatorname{affi}_{t}\right)=F\left(\xi_{t}^{l} ; \beta\right)+b_{t}, \quad \text { with } b_{t}=\frac{a_{t}}{1-B},
$$

so that the $\beta$ parameters will have direct interpretations on affi $i_{t}$ as discussed in Sect. 4.2 below. Model (4.1) incorporates all deterministic and autoregressive elements previously identified for employment flows in model (3.1), provided they are significant for the movements in the affiliation growth rate. The question is whether this series can grow to a greater or lesser extent throughout some of the sample periods. For this purpose, we estimate a Markov-switching model for the residuals in Eq. (4.1), that is,

$$
\nabla \log \left(\mathrm{affi}_{t}\right)-\nabla \widehat{\log \left(\mathrm{affi}_{t}\right)}=\mu_{S_{t}}+v_{t}
$$

where $\left.\nabla \widehat{\log (\text { affi }} i_{t}\right)$ is the right-hand side in (4.1) (the hat denotes "predicted"), $v_{t} \sim$ $N\left(0, \sigma_{v}^{2}\right)$ is assumed to be white noise, and $S_{\mathrm{t}}=\{1,2\}$ denotes two states with 
Table 2 The univariate time series model for the growth rate of affiliations. We include differenced dummies consistent with the model for the flows: D DAY Effect

\begin{tabular}{|c|c|}
\hline Variable & Coefficient \\
\hline Constant & $\begin{array}{l}5.08 \mathrm{E}-05 \\
(5.96 \mathrm{E}-05)\end{array}$ \\
\hline D MON Effect & $\begin{array}{l}0.000449 * * * \\
(6.11 \mathrm{E}-05)\end{array}$ \\
\hline D MON Beg of Mth & $\begin{array}{l}-0.00091 * * * \\
(0.000188)\end{array}$ \\
\hline D FRI Effect & $\begin{array}{l}-0.000475^{* * *} \\
(5.89 \mathrm{E}-05)\end{array}$ \\
\hline D End of Mth all Mths & $\begin{array}{l}\text { See Fig. } 5^{* * * *} \\
\text { (Next page) }\end{array}$ \\
\hline D Season Xmas & $\begin{array}{l}-0.001973 \text { *** } \\
(0.000366)\end{array}$ \\
\hline D Season Sun & $\begin{array}{l}0.00437 * * * \\
(0.000552)\end{array}$ \\
\hline D Mth January & $\begin{array}{l}-0.002404 * * * \\
(0.000527)\end{array}$ \\
\hline D Mth March & $\begin{array}{l}-0.002318^{* * * *} \\
(0.000622)\end{array}$ \\
\hline D Mth April & $\begin{array}{l}-0.001876^{* * * *} \\
(0.000518)\end{array}$ \\
\hline D Mth June & $\begin{array}{l}-0.001058^{* * * *} \\
(0.000395)\end{array}$ \\
\hline D Mth September & $\begin{array}{l}-0.001539 * * * \\
(0.000423)\end{array}$ \\
\hline D Mth December & $\begin{array}{l}0.003371 * * * \\
(0.00054)\end{array}$ \\
\hline $\operatorname{AR}(1,10)$ & Negative $* * *$ \\
\hline $\operatorname{AR}(19,20,21,22,23)$ & Positive*** \\
\hline Adjusted $R^{2}$ & 0.706145 \\
\hline S.E. of regression & 0.001158 \\
\hline Akaike info criterion & -10.6597 \\
\hline Schwarz criterion & -10.5346 \\
\hline Log likelihood & 7382.925 \\
\hline Durbin-Watson stat. & 1.97581 \\
\hline
\end{tabular}

transition probabilities $\operatorname{Pr}\left(S_{\mathrm{t}}=h \mid S_{\mathrm{t}}=h\right)=p_{\mathrm{hh}}$ and $\operatorname{Pr}\left(S_{\mathrm{t}}=i \mid S_{\mathrm{t}}=h\right)=1-p_{\mathrm{hh}}=$ $p_{\text {hi }}$.

\subsection{The incidence of calendar effects on employment growth}

Table 2 summarizes the estimates of the time series model for the affiliation growth rate. Although very stylized, the model accounts for about $70 \%$ of the variability. 


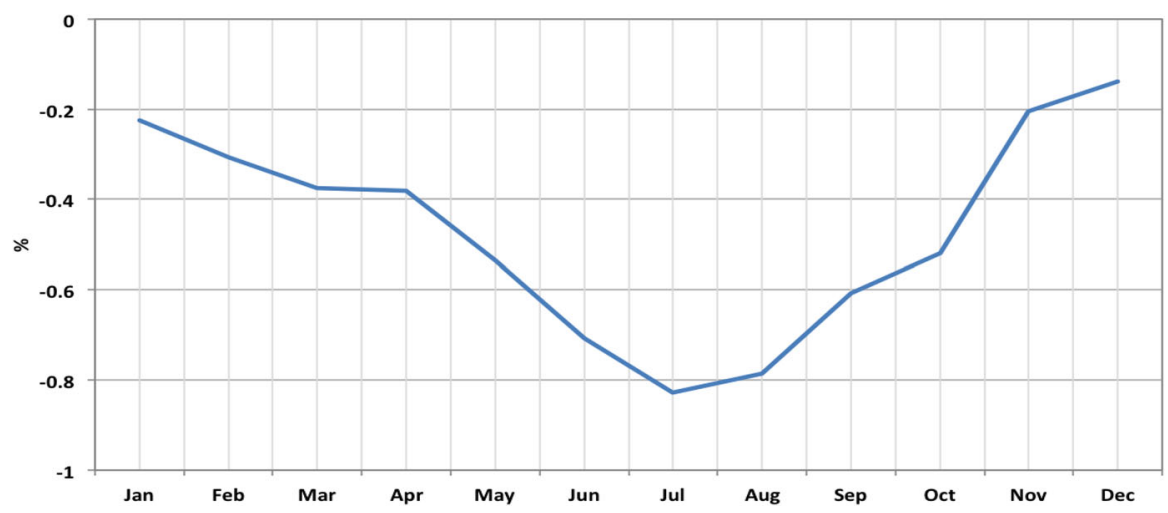

Fig. 5 Estimated average "end of month effect" on affiliations growth, all months

The autoregressive components are significant at monthly lags, but not particularly so below 20-23 days. Thus, we skip intra-month persistence profiles. There is now D(ifferenced), DUM 202, again to capture the negative affiliation growth the day after the 14 November 2012 general strike.

As expected, daily mean growth is not significantly different from zero. First, with respect to economic activity, the summer season is estimated on average $0.4 \%$ above mean growth. On the contrary, the holiday effect during Christmas seems to slightly dominate the activity effect, and affiliations growth is $0.2 \%$ below mean growth. Secondly, regarding calendar effects, we find that affiliation growth on Monday is positive, whereas the effect on Friday is negative and nearly the same size. This suggests an important fluctuation within the week, possibly capturing the strong incentive for firms to avoid extra salaries and social security contributions associated with weekends. Finally, Monday-and-beginning of month is also significant, and its effect on affiliation growth doubles that of the average Monday, but it does so with a negative sign. As before, this is due in part to the composition of Monday effects. However, notice now that in first-differences, we can only handle one in every two consecutive dummy variables, so here we must skip the Friday end of month effect and, in line with the previous discussion about Fig. 4, the negative sign may capture in part beginning of month destruction.

Nevertheless, the key deterministic effect on the growth rate of affiliations is the destruction of net employment by the end of each month. This effect is significant (except in December) and always negative, but it differs in magnitude for each and every month. Figure 5 reports the estimates and their strong yearly pattern. The effect is significantly higher from March to August. This reflects that the probability of affiliation destruction by the end of the month is higher along the calendar year. ${ }^{9}$ Does this reflect a combination of effects over the business cycle? Apparently, it does. A Markov-switching model for the residual of the calendar effects regression on the affiliation growth rate identifies a change of mean that is significant between two

\footnotetext{
9 The end of quarter effect is significant (but less) and negative, end of June and end of September, while positive end of March and end of December. The end of year effect is augmented with a positive beginning of year effect.
} 
Table 3 The Markov-switching model

\begin{tabular}{lcccc}
\hline Variable & Coefficient & Std. Error & $z$-Static & Prob. \\
\hline Regime 1 & & & \\
$\alpha_{1}$ & -0.003838 & 0.000275 & -13.96809 & 0.0000 \\
Regime 2 & & & \\
$\alpha_{2}$ & 0.000211 & $2.83 \mathrm{E}-05$ & 7.431043 & 0.0000 \\
Common & & & -324.9087 & 0.0000 \\
LOG(SIGMA) & -6.961807 & 0.021427 & 2 \\
\hline Transition matrix & & 1 & 0.900368 \\
& 1 & 0.099632 & 0.972904 \\
\hline All periods & 2 & 0.027096 & \\
& & & \\
\hline
\end{tabular}

regimes (see Table 3). There is a "normal" state most of the time and a state of low growth by the end of each month. The persistence of the low growth state, say Regime $1\left(\alpha_{1}=-0.00384\right)$, is a very low 0.0996 , whereas the persistence of Regime 2 is a very high 0.973 (with estimated mean $\alpha_{2}=0.00021$, close to zero). Figure 6 depicts the total number of affiliations (the raw daily time series), together with the probability of changes in the mean of the Markov-switching model (the vertical solid lines). The grid also depicts (dashed) both the end of months and years. It is apparent that since the beginning of the expansion, circa 2015, the probabilities of regime changes by the end of the month have increased. In fact, high probabilities are concentrated in the second half of the year, and they reflect a more intense destruction of contracts by the end of the month after each May throughout the expansion period. This is consistent with the pattern observed in Fig. 1b. Moreover, the estimated persistence parameters imply average durations of 1.2 days (Regime 1) and 36.9 days (Regime 2), respectively. That is, Regime 2 roughly corresponds to 2 months of weekdays, consistent with the fact that regime switches generally occur from May to October, that is, within 6 months.

To summarize, we find evidence of a regime switch in the employment growth rate, which systematically decreases by the end of each month. Such a regime switch intensifies in the second part of the year and as the economy moves further along the expansion period. This latter finding can be related to regional business cycle evidence as discussed in Camacho et al. (2017), for example. These authors show that the Islands and Valencia typically lead the cycle. The incidence of tourism employment in these regions is large, and this sector makes a good tracking of booms and busts in Spain. This feature rationalizes the interaction of the end of month effect with the business cycle we spot, and it motivates the following analysis of the occupational structure of calendar effects. 


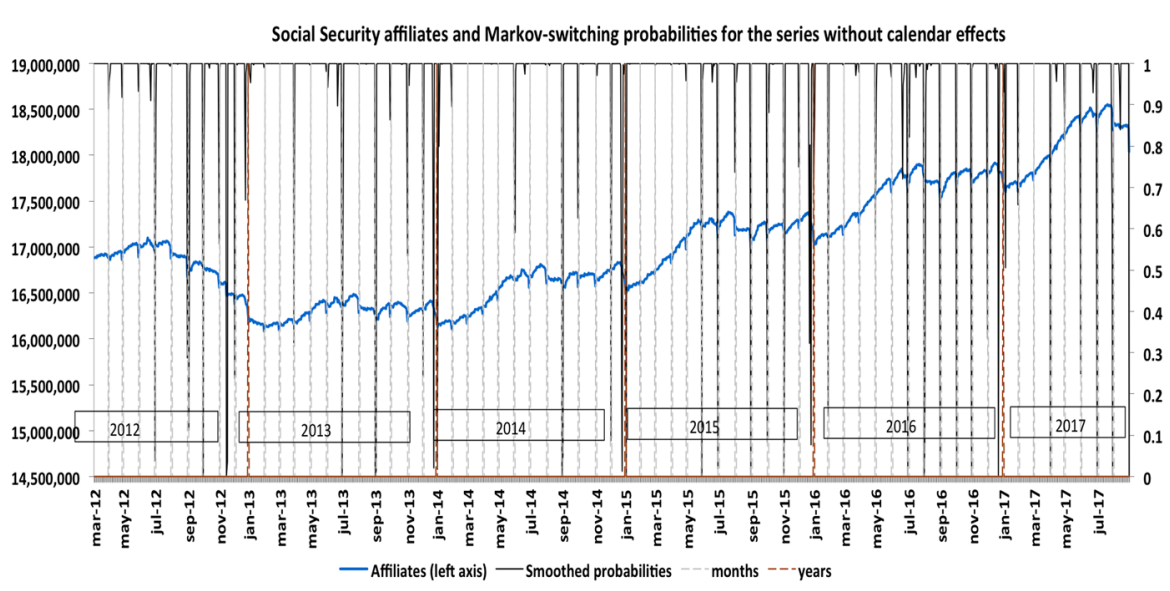

Fig. 6 Number of daily social security affiliations and estimated changes in the mean of affiliations growth, over the different years after calendar and autoregressive effects

\section{Sectoral composition and calendar effects}

This section investigates the cross-sectional determinants of the calendar effects we have identified. Among the alternative explanatory daily variables we might consider, we single out the effects of changes in the sectoral composition of new contracts registered in SEPE (Servicio Público de Empleo Estatal/Official Employment Information Administration). ${ }^{10}$ Precisely, we exploit the occupational structure of contracts to learn about the strength and variability of calendar effects. We select occupations rather than sectors in order to observe workers with higher disaggregation. Nevertheless, the combination of sector and category of occupations at two digits accounts well for the sectoral determinants of calendar effects we discuss. Moreover, as there are many occupations registered, even at two digits (the classification of occupations roughly follows the International Standard Classification of Occupations -ISCO-88; see "Appendix B," in particular, Table 9), we select the ones with more volume of contracts across time, which in its turn is very representative of key sectors. We initially restrict to occupations with more than 1000 contracts a day, on average over the sample. Using this selection, we cover nearly $75 \%$, on average, of the new contracts every day.

Our strategy is as follows. First, we regress the outcome variables, say measured aggregate either Monday or Friday effects, on the share of contracts for each sectorcategory of employment in the register. This shows that the strength of calendar effects is driven by some key occupations among those with more volume of contracts across time. Secondly, we estimate individual calendar effects for these key occupations and relate them with the incidence of temporary contracts. This identifies high temporary

\footnotetext{
10 Alternative daily data if available, confronted with different measures of calendar effects, could render relevant information for the design of policies to mitigate the high incidence of temporary contracts. Clearly though, the availability of data limits the possibility of considering alternative explanatory variables for the varying intensity of calendar effects. Registers of foreign visitors or hostel accommodation on a daily basis are good candidates.
} 
rates of employment in occupations displaying strong calendar effects. While fixedterm contracts are indeed an important source of calendar effects, they are not its only driver. Thus, we end by showing that the distortion in the records of affiliations and other administrative frictions, together with the differences in the technology and seasonality of demand across sectors, is also important drivers of the quantitative importance of the calendar effects we have identified.

\subsection{The contribution of the different occupations to calendar effects}

In Sect. 3, we used the aggregate daily series of new contracts to replicate the calendar effects obtained for employment creation. Let us recall that we solely paired new contracts with employment creation because we only have information on the starting dates of contracts. Here, we exploit the occupational structure of contracts to learn about the strength and variability of aggregate calendar effects. Aggregate calendar effects on employment creation are defined by the series we call filtered hirings in logs, say hirings ${ }_{t}{ }^{11}$ We construct,

$$
\widehat{\text { hirings }}_{t} \equiv \text { hirings }_{t}-\widehat{\text { hirings }}_{t}+\hat{\beta}^{\mathrm{ce}} \cdot \psi(B) \cdot \xi_{t}^{\mathrm{ce}}
$$

where hirings $\mathrm{s}_{t}-\widehat{\operatorname{hirings}}_{t}$ are the residuals in regression model (3.1-3.2), and $\hat{\beta}^{\mathrm{ce}}$. $\psi(B) \cdot \xi_{t}^{c e}$ is the estimated effect of the dummy variable $\xi_{t}^{\mathrm{ce}}$ in that regression model, weighted by the inverse lag polynomial in (3.2), with "ce" being Monday "me" or Friday "fe" effects. As before, we construct now filtered variables conditional on seasonal economic activity.

In particular, remember that for the log of employment creation model (see Table 1), the $\hat{\beta}^{\text {me }}$ is about 0.875 (s.e.: $0.0143 ; 0.869(0.0145)$ with seasonal economic activity dummies), whereas the $\hat{\beta}^{\text {fe }}$ is only 0.0236 (s.e.: $0.0141,0.0266(0.0146)$, respectively). Remember also that such a deterministic model explains more than $85 \%$ of the time series behaviour of the log of employment creation. Therefore, when we exclude the Monday effect, for instance, we are above $70 \%$ explanatory power for daily employment creation obtained from the rest of calendar and economic time dummies. The goal of our specification is first to compute linear correlations between the unexplained $30 \%$ contained in $\widetilde{\text { iirings }}_{t}$, that is, the reference calendar effect with the stochastic part, and the daily creation of contracts in various occupations. Once we construct the filtered

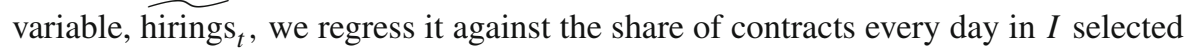
occupations partialling out the calendar effect under study. That is, we estimate,

$$
\widetilde{\text { hirings }_{t}}=\gamma \xi_{t}^{\mathrm{ce}}+\sum_{i=1}^{I} \delta_{j} s_{i t}+\eta_{t},
$$

\footnotetext{
11 We refer to "hirings" to stress the use of new contracts as explanatory variables. Thus, our empirical approach here makes use of the flows of contracts (wage-employed social security affiliates) to account for the variability of the filtered variable hirings$t$, built from employment creation. Therefore, by the result in Sect. 3 on calendar effects' smoothing through the self-employed, we provide a lower bound for the intensity in the comovement of occupations, since all calendar effects measured on employment creation are exacerbated if they are measured in new contracts (see again Table 1).
} 
where $\xi^{\mathrm{ce}}$ is a dummy variable for the corresponding calendar effect, and $s_{i t}$ is the share of contracts in occupation $i$ over the total of contracts in all of the $M>I$ selected occupations on each workday $t$. We control for autoregressive parts, $\eta_{t}$, to account for any remaining dynamic structure associated with selected occupations. We checked that omitted occupations are not relevant to account for the variability of $\widehat{\text { hirings }}_{t}$ once eliminated other deterministic components.

\subsubsection{Positive correlations with the calendar effects}

Table 4 reports the estimated parameters. Although coefficients are normalized (shares divided by its average), they are large for occupations with a relatively small average share of contracts. Thus, we primarily focus on the sign and significance of the estimates. We find that occupations positively correlated with the Monday effect (Table 4, top panel) are C96 (untrained workers/elementary occupations in construction and mining) and C97 (untrained workers in manufacturing); C51 (restaurant services) and C52 (shop assistants); and C22 (teaching and educational professionals) together with C37 (cultural and sport services) and C44 (leisure services). These are among the elementary occupations in their sectors (group 9, group 5) and thus typically under fixed-term contracts. ${ }^{12}$ Note that educational occupations involve teachers in primary, secondary, and both technical- and college-based higher education. Variability in these occupations arises because the bulk contracts in the educational sector are signed at the beginning of each academic year (see "Appendix B").

We could rank the contribution of occupations to the variability of the Monday effect in various ways. Figure 7 summarizes two simple proposals for the benchmark case, which is under specification (1) in Table 4. The left panel considers an alternative based on dropping the positively correlated sectors from the regression and then computing the joint adjusted- $R^{2}$ for the rest: It is 0.81 in the benchmark case. Then, we compute the relative explanatory gain for each occupation, adding them one by one, as reported in Fig. 7a. Proceeding this way, the gain with Manufacturing elementary (C97) and Restaurant Services (C51) is around 0.4\% each, whereas Educational (C22) alone represents a gain of more than $0.2 \%$. Sport and Leisure services give a $0.3 \%$ gain, but these are occupations with a lot within variability (from sport coaches to travel agents). Finally, the gain by Shop Assistants (C52) and Construction (C96) is low. The other ranking alternative approximates the adjusted linear simple regression, so we compute the standardized $\hat{\delta}$ 's instead. Figure $7 \mathrm{~b}$ reports these numbers in percentage terms. ${ }^{13}$ This sorting implies an overwhelming explanatory power for the restaurant services sector, now well above the elementary occupations in manufacturing. This suggests that even though elementary occupations seem to drive the Monday effect, these are transversal to various sectors of the economy and the Restaurant Services sector is a key driver of the huge episodes of volatility in employment flows we observe in the aggregate.

\footnotetext{
12 Fixed-term contracts in groups 5 and 9 are above $30 \%$ and $35 \%$, respectively, of the total number of daily new contracts of all types, on average over the sample.

13 The standardized $\hat{\delta}$ 's are the estimated coefficients times the standard deviation of the regressor relative to that of the dependent variable. The square to this value approximates the $\hat{\delta}$ of the simple linear regression and thus the percentage of variability explained by one regressor controlling for the other.
} 
Table 4 Linear relations between daily share of contracts in the different occupations and variability of either monday or friday effect in employment creation (with or w/o economic dummies)

\begin{tabular}{|c|c|c|c|c|}
\hline \multirow[t]{2}{*}{ Variable } & \multicolumn{4}{|c|}{ Regression specifications } \\
\hline & $\begin{array}{l}\text { Filtered Monday } \\
\text { Effect }\end{array}$ & $\begin{array}{l}\text { Filtered Monday } \\
\text { Effect econ }\end{array}$ & $\begin{array}{l}\text { Filtered Friday } \\
\text { Effect }\end{array}$ & $\begin{array}{l}\text { Filtered Friday } \\
\text { Effect econ }\end{array}$ \\
\hline Constant & & & $\begin{array}{l}1.7984 * * * \\
(0.3187)\end{array}$ & $\begin{array}{l}1.6554 * * * \\
(0.3178)\end{array}$ \\
\hline Own effect & $\begin{array}{c}0.7164 * * * \\
(0.0221)\end{array}$ & $\begin{array}{l}0.7215^{* * *} \\
(0.0219)\end{array}$ & $\begin{array}{l}0.1034 * * * \\
(0.0263)\end{array}$ & $\begin{array}{l}0.1265 * * * \\
(0.0260)\end{array}$ \\
\hline
\end{tabular}

Occupations significant and positively related with variability of monday effect in creation

\begin{tabular}{|c|c|c|c|c|c|}
\hline \multirow[t]{2}{*}{ Educational } & $\mathrm{C} 22$ & $2.3443 * * *$ & 0.5614 & 0.6525 & $-2.3787 * * *$ \\
\hline & & $(0.6984)$ & $(0.6944)$ & $(0.8586)$ & $(0.8571)$ \\
\hline \multirow{2}{*}{$\begin{array}{l}\text { Cultural and sport } \\
\text { services }\end{array}$} & $\mathrm{C} 37$ & $1.8902 * * *$ & $2.3437 * * *$ & -0.7721 & -0.0008 \\
\hline & & $(0.4392)$ & $(0.4361)$ & $(0.6203)$ & $(0.6203)$ \\
\hline \multirow[t]{2}{*}{ Leisure services } & $\mathrm{C} 44$ & $5.551 * * *$ & $5.4783 * * *$ & 0.7323 & 1.2783 \\
\hline & & (1.6749) & (1.6593) & $(1.7852)$ & (1.7737) \\
\hline \multirow{2}{*}{$\begin{array}{l}\text { Restaurant } \\
\text { services }\end{array}$} & C51 & $1.8045 * * *$ & $1.6244 * * *$ & $-1.6306^{* * *}$ & $-1.5260 * * *$ \\
\hline & & $(0.3500)$ & $(0.3472)$ & $(0.4320)$ & $(0.4297)$ \\
\hline \multirow[t]{2}{*}{ Shop assistants } & C52 & $1.9354 * * *$ & $1.3836^{*}$ & -1.5434 & $-1.7983^{*}$ \\
\hline & & $(0.3500)$ & $(0.7488)$ & $(0.9440)$ & $(0.9484)$ \\
\hline \multirow{2}{*}{$\begin{array}{l}\text { Construction } \\
\text { (elementary) }\end{array}$} & C96 & $3.3154 * * *$ & $3.0927 * * *$ & 0.7523 & -1.4674 \\
\hline & & $(0.8613)$ & $(0.8494)$ & $(0.9373)$ & $(0.9261)$ \\
\hline \multirow{2}{*}{$\begin{array}{r}\text { Manufacturing } \\
\text { (elementary) }\end{array}$} & $\mathrm{C} 97$ & $3.1963 * * *$ & $3.1993 * * *$ & -0.5936 & 0.3456 \\
\hline & & $(0.5544)$ & $(0.5474)$ & $(0.6991)$ & $(0.6993)$ \\
\hline
\end{tabular}

Occupations significant and negatively related with variability of Monday in creation

\begin{tabular}{|c|c|c|c|c|c|}
\hline \multirow{2}{*}{$\begin{array}{l}\text { Artistic, literary } \\
\text { and cultural }\end{array}$} & $\mathrm{C} 29$ & $-2.6644 * * *$ & $-2.6505^{* *}$ & $-3.1127 * * *$ & $-3.2129 * * *$ \\
\hline & & $(1.0151)$ & (1.0113) & $(1.0035)$ & (1.0107) \\
\hline \multirow{2}{*}{$\begin{array}{l}\text { Sellers out of } \\
\text { shops }\end{array}$} & $\mathrm{C} 54$ & $-1.4388^{*}$ & $-1.3248^{*}$ & $-2.5975^{* * *}$ & $-2.7077 * * *$ \\
\hline & & $(0.8070)$ & $(0.8001)$ & $(0.9347)$ & $(0.9302)$ \\
\hline \multirow{2}{*}{$\begin{array}{l}\text { Construction } \\
\text { (skilled) }\end{array}$} & C71 & $-4.3996 * * *$ & $-3.7772 * * *$ & $-7.7936^{* * *}$ & $-6.6604 * * *$ \\
\hline & & $(0.9451)$ & $(0.9365)$ & (1.1180) & $(1.1200)$ \\
\hline \multirow[t]{2}{*}{ Domestic cleaning } & C91 & $-2.1960 * *$ & $-1.6976^{*}$ & $-5.5494 * * *$ & $-5.5324 * * *$ \\
\hline & & (1.0393) & $(1.0371)$ & (1.0843) & $(1.1152)$ \\
\hline \multirow[t]{2}{*}{ Food preparation } & C93 & $-10.9455^{* * *}$ & $-10.1531 * * *$ & $-3.5495^{*}$ & $-4.2911 * *$ \\
\hline & & $(2.2420)$ & $(2.2165)$ & $(1.9685)$ & $(1.9702)$ \\
\hline
\end{tabular}


Table 4 continued

\begin{tabular}{|c|c|c|c|c|c|}
\hline \multirow[t]{2}{*}{ Variable } & & \multicolumn{4}{|c|}{ Regression specifications } \\
\hline & & $\begin{array}{l}\text { Filtered Monday } \\
\text { Effect }\end{array}$ & $\begin{array}{l}\text { Filtered Monday } \\
\text { Effect econ }\end{array}$ & $\begin{array}{l}\text { Filtered Friday } \\
\text { Effect }\end{array}$ & $\begin{array}{l}\text { Filtered Friday } \\
\text { Effect econ }\end{array}$ \\
\hline $\begin{array}{l}\text { Storage and shelf } \\
\text { filers }\end{array}$ & C98 & $\begin{array}{l}-14.4442 * * * \\
(1.4533)\end{array}$ & $\begin{array}{l}-15.3502 * * * \\
(1.4396)\end{array}$ & $\begin{array}{l}-11.7850 * * * \\
(1.3819)\end{array}$ & $\begin{array}{l}-12.4295^{* * *} \\
(1.3763)\end{array}$ \\
\hline \multicolumn{6}{|c|}{ Occupations significant for variability of Friday effect in creation, always negatively related } \\
\hline Health & $\mathrm{C} 21$ & $\begin{array}{l}-1.4358 \\
(0.9450)\end{array}$ & $\begin{array}{l}-1.4845 \\
(0.9360)\end{array}$ & $\begin{array}{l}-3.4641 * * * \\
(0.9898)\end{array}$ & $\begin{array}{l}-3.4220 * * * \\
(0.9839)\end{array}$ \\
\hline Caring & C56 & $\begin{array}{l}-0.8572 \\
(1.6042)\end{array}$ & $\begin{array}{l}-0.6002 \\
(1.5855)\end{array}$ & $\begin{array}{l}-7.1797 * * * \\
(1.6924)\end{array}$ & $\begin{array}{l}-6.6716^{* * * *} \\
(1.6908)\end{array}$ \\
\hline \multirow{2}{*}{$\begin{array}{l}\text { Agricultural } \\
\text { (elementary) }\end{array}$} & C95 & 0.1641 & $0.2008^{*}$ & $-1.6572^{* * *}$ & $-1.4674 * * *$ \\
\hline & & $(0.1130)$ & $(0.1134)$ & $(0.3555)$ & $(0.3534)$ \\
\hline $\operatorname{AR}(1,20)$ & & & & $* * *, *$ & $* *, * *$ \\
\hline $\operatorname{AR}(5,9,22)$ & & $* * *$ & $* * *$ & $* * *$ & $* * *$ \\
\hline $\operatorname{AR}(7,14)$ & & $* *, * * *$ & $*, * *$ & $* * *$ & $* *$ \\
\hline Adjusted $R^{2}$ & & 0.833519 & 0.836452 & 0.199500 & 0.195163 \\
\hline S.E. of regression & & 0.166219 & 0.164258 & 0.166384 & 0.164346 \\
\hline $\begin{array}{l}\text { Akaike info } \\
\text { criterion }\end{array}$ & & -0.7311781 & -0.755516 & -0.727602 & -0.752246 \\
\hline Schwarz criterion & & -0.630755 & -0.654490 & -0.614920 & -0.639563 \\
\hline Log likelihood & & 515.5613 & 531.4399 & 515.7660 & 532.2552 \\
\hline $\begin{array}{l}\text { Durbin-Watson } \\
\text { stat. }\end{array}$ & & 2.019701 & 1.967448 & 2.010655 & 2.005060 \\
\hline
\end{tabular}

Standard errors in parentheses. ${ }^{*} p<0.10 ;{ }^{* *} p<0.05 ;{ }^{* * *} p<0.01$. All nonsignificant C58-84-92-94

Notice that, as indicated, the ranking differs from the one resulting from the size of the estimates. Our strategy here is to keep a simple methodological approach to illustrate the findings. One may consider instead various counterfactuals for the purpose of more elaborated policy recommendations. Finally, small differences are present when we study the measured Monday effect conditional on seasonal economic activity. Specification (2) in Table 4 shows, as expected, that most coefficients usually diminish. Yet, C95 (agricultural occupations) becomes significant once we control for seasonal patterns. We interpret these findings as evidence of certain occupations driving the variability (spikes) of episodic movements in hirings. At the same time, however, some occupations comove against the identified calendar effects, as we discuss next.

\subsubsection{Other correlations}

The correlation of some occupations with the variability of episodic over-hiring may also be negative. This simply means that job creation in some occupations correlates negatively with new contracts in the sector categories driving the Monday effect. This 


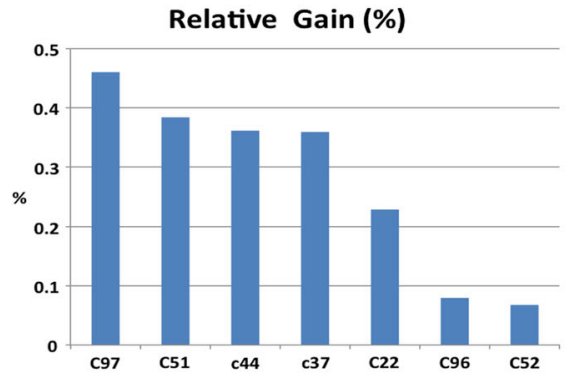

(a) Adjusted $R^{2}$ based measure

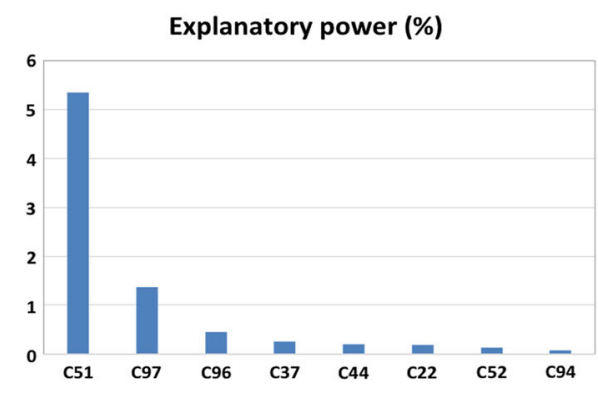

(b) Standardized $\hat{\delta}^{\prime} s$ based measure

Fig. 7 Ranking of explanatory power of the variability of the Monday effect for different occupations, 2012-2017. Note units are per cent in both cases, but not comparable

happens, for instance, with C91 (domestic cleaners), C93 (food preparation), and C98 (storage and shelf filers), as well as C54 (sellers out of shops and stores). Clearly, preparation activities in shops or food stores go before the sales. Likewise, domestic cleaners seem to appear when activity in the market cleaning sector declines. Thus, the reported evidence seems consistent with basic intuitions. The tension between occupations C71 (Construction skilled) and C96 (Construction elementary) is particularly interesting. Monday seems to be a bad day to bring plumbers, carpenters, or glaziers to the building trade, but apparently, it is the hiring day for all kinds of assistants to these occupations.

We do not find evidence that new contracts in occupations such as C92 (cleaning) and C94 (elementary occupations in services), or C84 (urban and road transport drivers) are significant for the movements in the filtered, either Monday or Friday, variables. Alternatively, movements in occupations, such as C21 (health professionals, from doctors to therapists), C56 (caring), and C95 (elementary agricultural), are only significant for the Friday effect on hiring, and again, with a negative sign. All these occupations, apart from exhibiting substantial within variance in some cases, have no such a clear pattern associated with the workweek as do the occupations highlighted above, and clearly, they are not "Friday intense." More in general, specifications (3) and (4) in Table 4 report the corresponding correlations for the Friday effect in hirings, and the most salient feature is that correlations across occupations are either negative or nonsignificant. This may suggest that these occupations determine the variability of firing (an information missed in contracts) rather than hiring. Notice that, conditional on seasonal economic activity, the estimated negative correlations now increase.

In particular, the Restaurant Services sector also exhibits a significant negative correlation with the variability of job creation on Friday. Our interpretation is twofold. First, given that contracts in restaurant services are found to be positively correlated with the Monday effect, it is the economic activity during the workweek, not the leisure activity during the weekends, which drives contracts in this sector. Secondly, given that contracts in restaurant services are negatively correlated with the Friday effect in hirings, it is the case that Friday hirings are relatively high when the share of contracts in the restaurant services occupations is low; this occurs mostly out of summer. The 
same thing happens with the educational sector conditional on seasonal activity. The Friday effect is strong when the educational sector makes no hires, provided the Friday effects are already smoothed over the calendar year and as far as Summer, Christmas, or the agricultural season is uninformative. Thus, one may wonder about the importance of calendar effects by occupations, as we do next.

\subsection{Occupational calendar effects, temporary rates and number of contracts}

Having introduced the different daily series of new contracts by occupations as explanatory variables, we may now consider the disaggregated calendar effects across some key occupations. To this end, we implement the exact calendar effects' regression specified for the aggregates in Eqs. (3.1-3.2) to each and every sector-category of employment at SEPE (results are available upon request). Then, we retain the direct calendar effects $\hat{\beta}_{i}^{\text {ce }}$ for the $i=1, \ldots, I$ selected occupations in the sample.

To summarize our findings, we first relate calendar effects with the population of workers under fixed-term contracts in the different occupations. Figure 8 plots the scatter of the estimated coefficients for the direct Monday effect in each occupation $i$, that is, the $\hat{\beta}_{i}^{\text {me }}$, with their corresponding temporary rates, computed as a weighted average of the temporary rates in the various sectors each occupation spreads. Figure 8a shows the scatter for all selected occupations. The Monday effect is relatively strong for most occupations, as highlighted in Fig. 8b. The key finding is that occupations with stronger Monday effects exhibit relatively high temporary rates. We fit to the scatter an order two polynomial with a $95 \%$ confidence interval. Noteworthy are the labels for the different occupations in Fig. 8b. On the other hand, going back to Fig. 8a, we may see that the few outliers $\left(\hat{\beta}^{\text {me }}<1.2\right)$ can be easily justified. For instance, we have already shown (see Table 4 , and discussion above) that agricultural and domestic cleaning occupations are not correlated with the aggregate Monday effect. This is quite consistent with the basic intuition. Also, the educational sector is different, as may be seen in Fig. 10c. Finally, it is not surprising to find occupations in the construction sector away from the northwest scatter during the post-housing boom period.

It may be argued, however, that the temporary rate is an imperfect measure of labour turnover. An alternative measure used in the literature is the number of contracts per new employee. So we compute such a number by occupation per year and then its average over the period 2012-2017. Figure 9 shows that occupations exhibiting a stronger direct Monday effect also have a higher average number of contracts per employee. That is to say, they present a higher prevalence of short-term contracts in the flow rather than the stock (as reflected by the temporary rate above). Of particular interest seems the position of occupations in the Health and Caring sector and Accommodation and Restaurant Services activity (see also Fig. 2a). Again, the only exception is in the primary sector (agriculture), where employment flows do not exhibit such a strong Monday effect for the given measure of labour turnover. This may be due to the role of the climatology, as discussed above. 


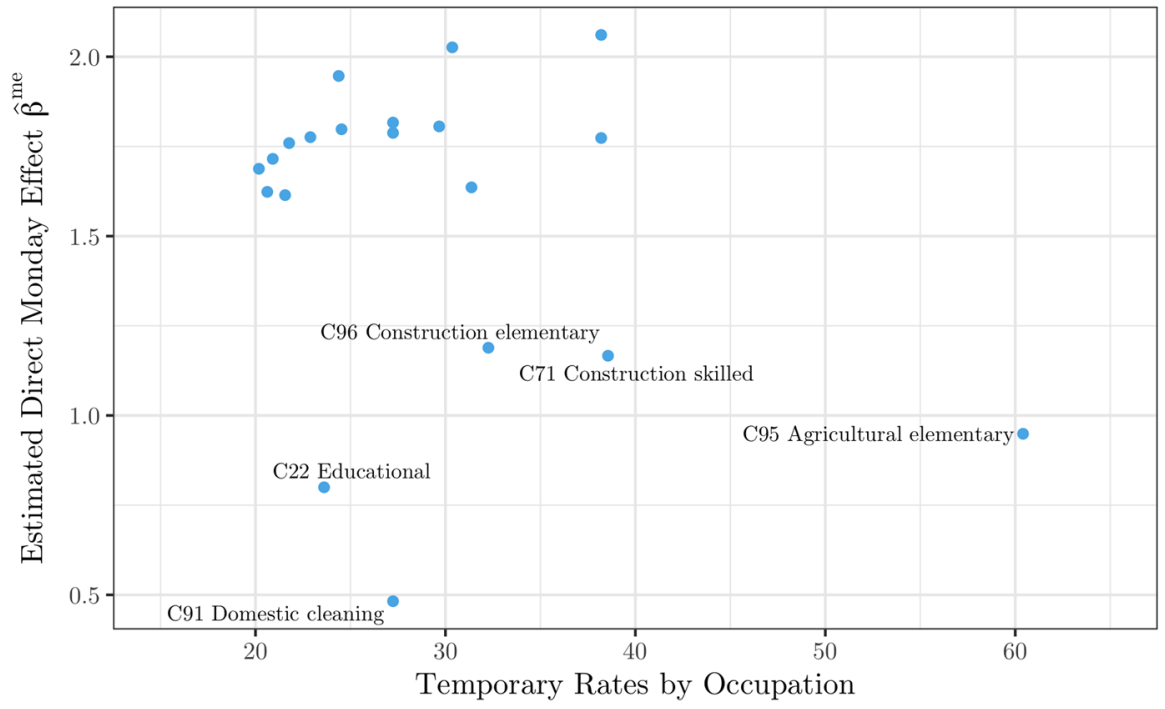

(a) Selected occupations, all $\beta$ 's

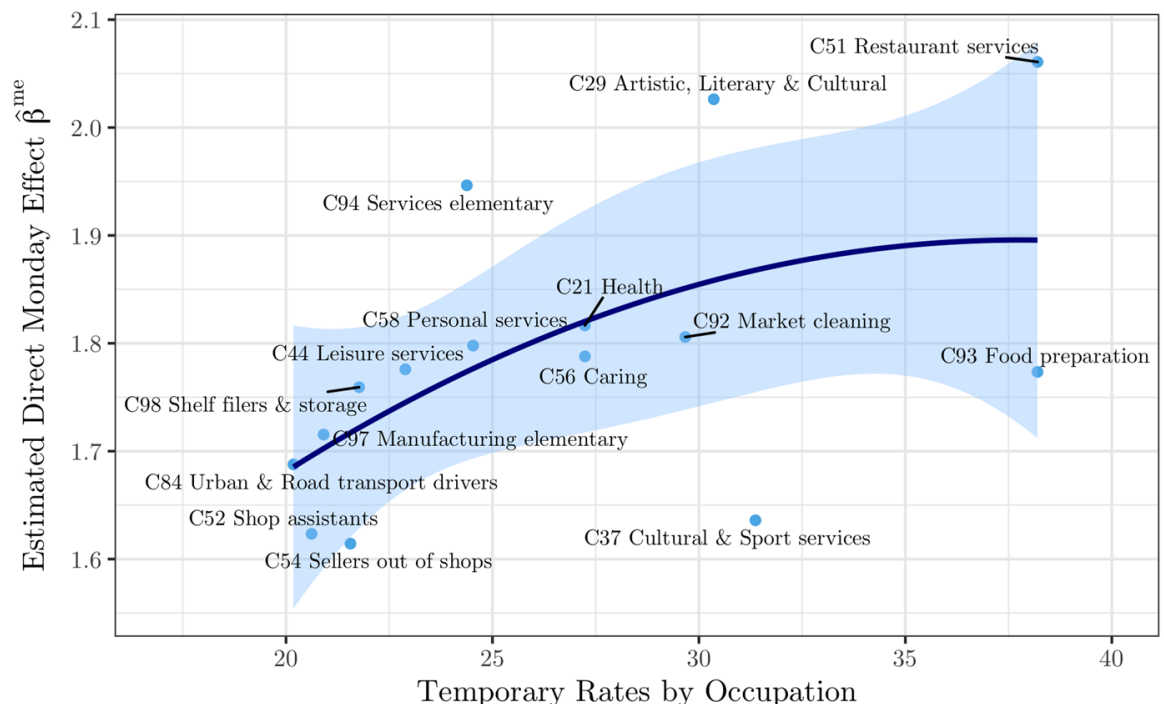

(b) Selected occupations, selected $\beta$ 's

Fig. 8 Average temporary rate and the direct monday effect by occupation, 2012-2017

\subsection{On the sources of calendar effects}

We have provided evidence that the prevalence of fixed-term contracts is correlated with calendar effects across occupations. Therefore, we expect temporary workers' contracts to be an important driver of calendar effects. Also, there are differences in 


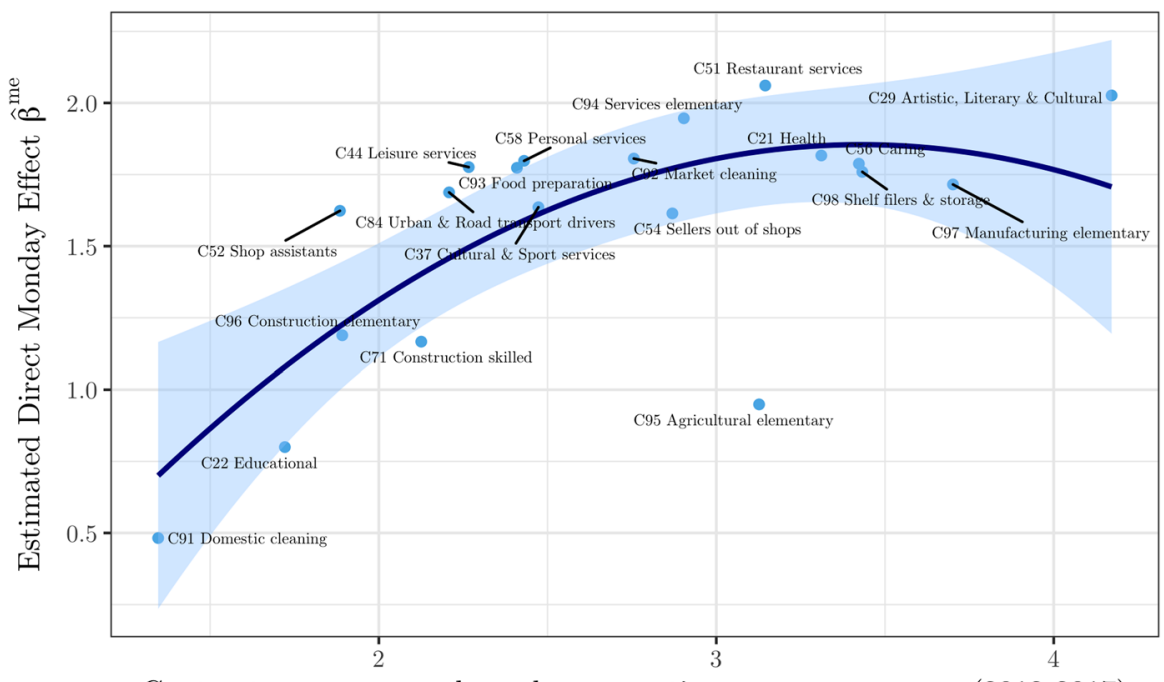

Contracts per new employee by occupation per year, average (2012-2017)

Fig. 9 Average contracts per new employee and the direct monday effect by occupation, 2012-2017. All $\beta$ 's from selected occupations included

the technology and the seasonality of demand across sectors that contribute to calendar effects, typically through employment flows in key occupations. Finally, there is the distortion in the records of affiliations due to only weekday register that contributes to measured calendar effects. This distortion in the register combines with other administrative frictions as well as with any labour market practices of an administrative nature. Can we assess the relative importance of these three sources of calendar effects? Namely those (i) owed to the distortion in the register and other administrative frictions, (ii) resulting from skill differences across occupations, and (iii) induced by temporary workers.

To answer this question we solely rely next on contract data. We make use of the gap between the original series and the series that stacks the weekend and holiday flows of contracts to the first subsequent weekday (the one which is comparable with the affiliation data). Actually, we retain a "restricted" original series to analyse: original but restricted to weekday not holiday. Notice further that both the "stacked" contract series and the "original restricted" series can be constructed for permanent and temporary workers and also across occupations, as we do now. ${ }^{14}$

For the targeted decomposition, we proceed as follows. First, we implement again the calendar effects regression (3.1) for (benchmark, i.e. stacked) contracts, say

\footnotetext{
14 Again, the good thing about working with contracts is that they are registered everyday, but the bad thing is that self-employed workers are excluded. Thus, by using the original contracts series "restricted", we miss the information on calendar effects for the self-employed workers and employed workers whose contract starts either on the weekend or on holidays. Also, we could estimate the Monday effect in the original series of contracts (say, "unstacked"), or in the "restricted original" series, but this would clearly require a different model, other than (3.1).
} 
contracts $_{t} \equiv c_{t}$, in logs, but now we do so under an exact decomposition of the Monday effect dummy that consists of,

$$
\beta_{\mathrm{M}} x_{t}^{\mathrm{M}} \equiv \beta_{\mathrm{M}}^{\mathrm{d}} \times\left[x_{t}^{\mathrm{M}} \cdot\left(\frac{c_{t}-c_{t}^{\mathrm{r}}}{c_{t}}\right)\right]+\beta_{\mathrm{M}}^{\mathrm{P}} \times\left[x_{t}^{\mathrm{M}} \cdot\left(\frac{c_{t}^{\mathrm{r}, \mathrm{P}}}{c_{t}}\right)\right]+\beta_{\mathrm{M}}^{\mathrm{T}} \times\left[x_{t}^{\mathrm{M}} \cdot\left(\frac{c_{t}^{\mathrm{r}, \mathrm{T}}}{c_{t}}\right)\right]
$$

where $c_{t}^{\mathrm{r}}$ denotes the original contract series "restricted" (to weekday not holiday), and $c_{t}^{\mathrm{r}, X}$, with $X=P$ or $T$ denotes the same series for either permanent or temporary workers. Remember that $x_{t}^{\mathrm{M}}$ is the Monday dummy variable. Therefore, $\hat{\beta}_{\mathrm{M}}^{\mathrm{d}}, \hat{\beta}_{\mathrm{M}}^{P}, \hat{\beta}_{\mathrm{M}}^{\mathrm{T}}$ decompose the direct Monday effect originally estimated, $\hat{\beta}_{\mathrm{M}}$, into three Monday effect components: the (d)istortion in the register on the one hand and the contribution of the original restricted Monday contracts of both (P)ermanent and (T)emporary workers. These components account for the variability of the corresponding variable on each and every Monday in the sample.

Table 5 summarizes the main findings in this section, together with a few related results on the Monday effect we already discussed in Sect. 3. The left panel refers to the calendar effects for affiliations and the right panel refers to contracts. The table also includes the results for the decomposition of the Monday effect, which is for contracts only.

First, the $\beta_{0}, \beta_{\mathrm{M}}$, and $\bar{\beta}_{\mathrm{M}}$ estimates for employment creation flows and contracts in Table 5 are already discussed in Sect. 3, except for one: the direct (conditional) Monday effect in the original contract series restricted to weekdays not holidays, $c_{t}^{\mathrm{r}}$, which is $\beta_{\mathrm{M}}^{\mathrm{r}}=0.5342$ (under the column "Restricted" and to be compared to $\beta_{\mathrm{M}}=1.0012$ ), with $\beta_{0}^{\mathrm{r}}=10.71$ (vs $\beta_{0}=10.63$ ). This implies that the direct Monday effect is $5 \%$ above the average day for undistorted but restricted contracts (vs $9.4 \%$ above the average day for stacked contracts). Also, the average effect, $\bar{\beta}_{\mathrm{M}}$, is $5.5 \%$ above for the former (vs $10.2 \%$ for the latter). These effects were about $8 \%$ for the affiliations series, as reported again here. We take these numbers for the original restricted contracts as a lower bound of the Monday effect (abstracting from self-employed and weekend flows). This suggests that more than $50 \%$ of the calendar effect on flows remains without any distortion in the register. Results for other calendar effects are available upon request.

With these numbers in mind, we can now discuss the decomposition results. The first row in the far right block of Table 5 reports the estimates of empirical model (3.1) for stacked contracts under the $\beta_{\mathrm{M}}$ specification in Eq. (5.3). The estimates are reported in comparable units, that is, as $\beta \cdot \bar{x}$, for each component $x$, over mean $\bar{x}$. At this first stage, in terms of the shares of the effect, we obtain that $60 \%$ of the Monday effect comes from the variability in temporary worker contracts, whereas $40 \%$ comes from the distortion in the register. ${ }^{15}$ Notice, however, that the permanent workers'

\footnotetext{
15 As a robustness check, we regress the filtered contracts variable (that is the variable Monday effect in contracts, defined as in Eq. (5.1): contracts $t$ ), against the single Monday dummy of each of the components (that is, now $x_{t}^{\mathrm{M}} \times c_{t} / c_{t}^{\mathrm{o}, \mathrm{r}}, c_{t}^{\mathrm{o}, \mathrm{r}, \mathrm{P}}, c_{t}^{\mathrm{o}, \mathrm{r}, \mathrm{T}}$, respectively, all in logs as the dependent variable is, and standardized to make units comparable). This new regression includes either or not the deterministic Monday dummy as a control. With this metric and including the deterministic Monday dummy, the distortion in the
} 


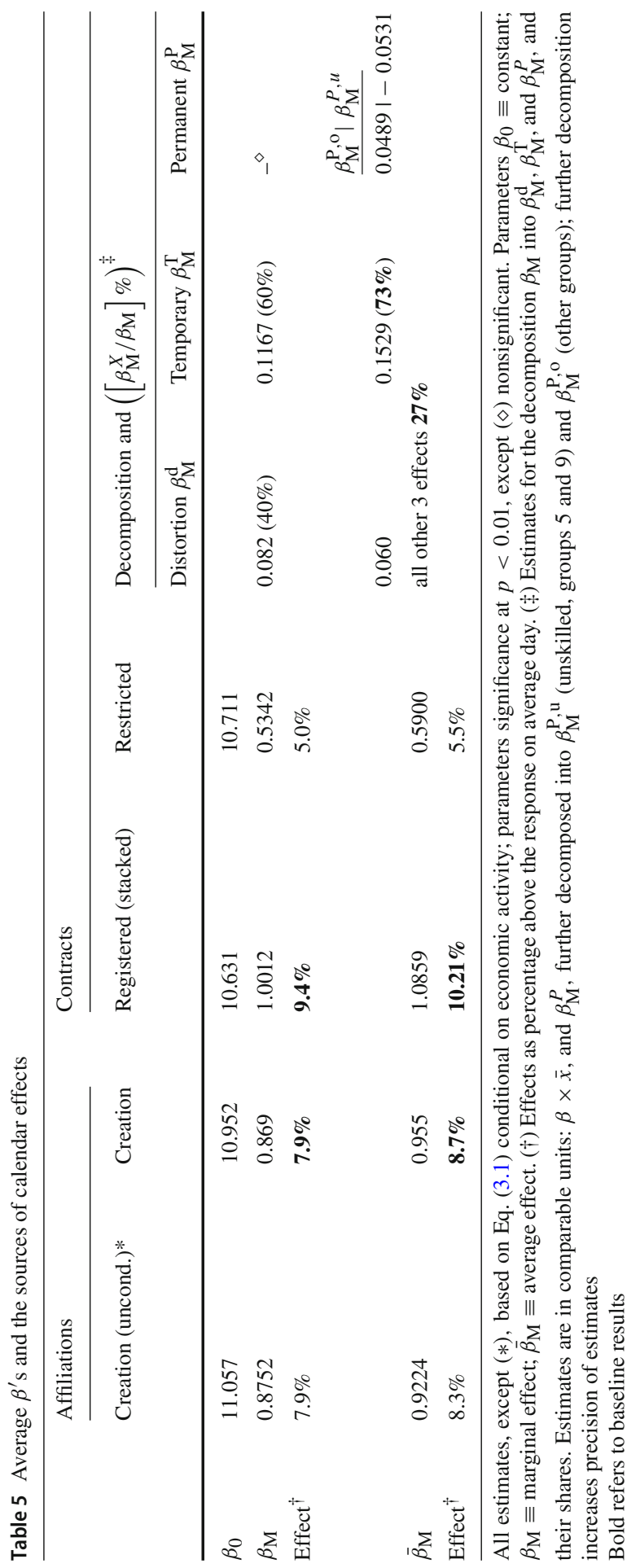


contracts variable, $c_{t}^{\mathrm{r}, \mathrm{P}} / c_{t}$, is not significant. This is why we consider an extension of the decomposition in Eq. (5.3) for $X=P$ or $T$ of the form:

$$
\beta_{\mathrm{M}}^{X} \times\left[x_{t}^{\mathrm{M}} \cdot\left(\frac{c_{t}^{r, X}}{c_{t}}\right)\right]=\sum_{i} \beta_{\mathrm{M}}^{X, i} \times\left[x_{t}^{\mathrm{M}} \cdot\left(\frac{c_{t}^{r, X, i}}{c_{t}}\right)\right], \text { for } X=P \text { or } T, i=1, \ldots, I .
$$

For instance, we could decompose the direct Monday effect from variation in temporary contracts $\beta_{\mathrm{M}}^{\mathrm{T}}$, into the $\beta_{\mathrm{M}}^{\mathrm{T}, i}$ for the $I$ selected occupations and the rest. However, this strategy is not very useful, because most occupations have a huge flow of temporary (above 90\%) versus permanent contracts. Instead, we simply decompose the $\beta_{\mathrm{M}}^{P}$, into the contribution of the variability of two sets of contracts. We call unskilled workers, $u$, the workers that sign contracts in group 5 and 9 occupations (see discussion in Sect. 5.1 above and "Appendix B"), so we put these contracts in variable $c_{t}^{\mathrm{P}, \mathrm{u}} / c_{t}$, and we put in $c_{t}^{\mathrm{P}, \mathrm{o}} / c_{t}$ the contracts for all the (o)ther occupations. The finding is that for $\hat{\beta}_{\mathrm{M}}^{P}$, which is nonsignificant in the aggregate, the components become significant with nearly the same value and opposite signs. Moreover, the positive effect, $\hat{\beta}_{\mathrm{M}}^{\mathrm{P}, \mathrm{o}}$, is nearly the same size as the estimated effect of the distortion $\hat{\beta}^{\mathrm{d}}$. We interpret that movements in permanent contracts on each and every Monday for "all-but-definitely unskilled occupations" may account for the contribution of labour market practices (institutional factors) to the Monday effect (that is, part of source "(i)" above). This result is obtained once we control for the effects of the distortion in the register (the other part of source (i)), the temporary contracts (source (iii) above), and finally, all other deterministic and stochastic components of the contract data generating process. Moreover, we interpret the negative sign for $\hat{\beta}_{\mathrm{M}}^{\mathrm{P}, u}$, as a measure of the role of technology in the Monday effect (part of source (ii) above). The idea is that unskilled permanent workers sign their contracts when necessary, regardless the day of the week. We consider this second estimation with the $\hat{\beta}_{\mathrm{M}}^{\mathrm{P}, o}$, and $\hat{\beta}_{\mathrm{M}}^{\mathrm{P}, u}$, as our benchmark decomposition outcome, so $73 \%$ is an upper bound for the contribution of new temporary worker contracts. We leave any additional decomposition at the occupational level for further research, and we conclude that short-term contracts are indeed the most important source of the Monday effect. Nevertheless, our findings suggest that there is a lot to be learned on the interaction between administrative labour market practices and the occupational structure of the economy. In particular, Conde-Ruiz et al. (2018) design an econometric framework to quantify, for the different occupations, potential nonlinearities in the strength of calendar effects along the calendar year.

Footnote 15 continued

register, $c_{t} / c_{t}^{\mathrm{o}, \mathrm{r}}$, becomes nonsignificant: This implies the effect of the distortion is mostly deterministic, so all weekend hirings are alike. On the other hand, without the deterministic Monday control in the regression, the variability of the Monday effect is explained (adjusted- $R^{2}$ ) in a $64 \%$ by the distortion, vs either a $58 \%$ by temporary or $38 \%$ by permanent worker components. 


\section{Concluding remarks}

The goal of this paper is to analyse when and how the huge episodes of aggregate employment creation and destruction observed in the Spanish labour market occur. We document that these episodes follow fixed-term contracts associated to the calendar on a daily basis. Calendar effects are shown to vary over the business cycle and along the calendar year, driven by a number of occupations that are very representative of the sectoral composition of the Spanish economy over the last decades. Our evidence is a key feature present in the most recent data that should be incorporated in the design of public policies aimed at forcing firms to internalize the cost of their excessive lay-offs.

Daily data illustrate the extent to which firms use contracts of a very short duration under intense Monday and Friday effects. The Monday effect on employment creation nearly doubles the average day effect unconditionally, whereas the Friday effect on employment destruction is roughly $20 \%$ above this average. These effects intensify every year during the summer and along the business cycle expansion. Thus, conditional on seasonal economic activity, autocorrelated components, and other deterministic effects, we estimate an average Monday effect on employment creation which is $10 \%$ above the average weekday effect. The measurement of the impact of each sector on the Monday and Friday effects of employment creation identifies five suspects: the construction sector (both elementary and skilled occupations), restaurant services, unskilled workers in manufacturing, and the educational occupations that add to the list in a tricky way. On the other hand, we find that occupations with stronger calendar effects exhibit higher temporary rates and excessive labour turnover. Identifying the contribution of various sources of calendar effects, we find that about two-thirds of the Monday effect for employed workers comes from temporary contracts, whereas the rest can be attributed equally to administrative frictions associated with labour market practices and the distortions in the register.

To the best of our knowledge, we are the first to use daily aggregate data from the labour demand side to analyse calendar effects in the labour market. Our results are consistent with some well-known findings from the labour supply side, such as the high labour turnover, the disproportionate use of fixed-term contracts, or the recent increase of contracts of very short-duration even when signed as permanent. Our approach, however, associates these findings to the business cycle and the sectoral composition of the economy, mostly through turnover in the elementary segment of several occupations. We conclude that there is a lot to be learned on employment volatility from the interaction between administrative labour market practices and the occupational structure of the economy.

We document an increase in employment creation and destruction in recent years, together with an upsurge in short-duration contracts. It is important to understand the reasons behind this. We see our analysis as a necessary step to this end, but further research is needed to investigate whether the identified calendar effects are backed by the same or different workers. Finally, it would be interesting to examine the extent to which these effects prevail in labour markets released from such temporary hiring. The type of zero-hour contracts that exist in the UK or the Netherlands, or the use of transitions to and from self-employment, might be playing a role akin to that of fixed-term contracts in Spain. Even though the status of this type of employment is 
equally precarious for workers, we may expect they produce much smoother spikes than the calendar effects we have identified.

Funding Spanish Ministerio de Economía y Competitividad (Grant ECO2016-76818) and Bank of Spain (Grant Excelencia 2016-17).

\section{Compliance with ethical standards}

Conflict of interest The authors declare that they have no conflict of interest.

Ethical approval This article does not contain any studies with human participants performed by any of the authors.

Informed consent For this type of study, formal consent is not required.

Open Access This article is distributed under the terms of the Creative Commons Attribution 4.0 International License (http://creativecommons.org/licenses/by/4.0/), which permits unrestricted use, distribution, and reproduction in any medium, provided you give appropriate credit to the original author(s) and the source, provide a link to the Creative Commons license, and indicate if changes were made.

\section{Appendix}

\section{A Aggregate employment data}

Social security registers The daily time series data contain information of the starting date and the termination date of all employment spells occurred in Spain during 20122017. The data consider both employed workers and self-employed. For this reason, we refer to these employment data flows as creation and destruction. The daily time series are constructed using social security records. We are going to use three different daily time series. The first is the daily number of affiliates to Social Security. The second (third) is the number of new registrations (number of de-registrations) daily to Social Security. Again, we interpret the number of new registrations as job creation and the number of de-registration as job destruction. The data have been obtained from the monthly publications of the Ministry of Labour and Social Security "Afiliación a la Seguridad Social". It is important to take into account that the register process only occurs on weekdays. In other words, the register data will only coincide with real data if the starting or the termination date occurs on a weekday. If the starting date or the termination date is either weekend or bank holiday, the register will be recorded on the first subsequent weekday (see Tables 6, 7, 8). 
Table 6 Job creation and destruction, averages annually

\begin{tabular}{|c|c|c|c|c|c|c|}
\hline & 2012 (from march) & 2013 & 2014 & 2015 & 2016 & 2017 \\
\hline \multicolumn{7}{|c|}{ Start date (employment creation) } \\
\hline Year & $16,171,565$ & $19,856,240$ & $22,029,130$ & $24,218,649$ & $26,026,851$ & $18,070,484$ \\
\hline Month & $1,608,134$ & $1,654,687$ & $1,835,761$ & $2,018,221$ & $2,168,904$ & $2,306,501$ \\
\hline Day & 77,748 & 79,109 & 87,765 & 96,489 & 103,281 & 106,926 \\
\hline Affiliations & $16,442,681$ & $16,357,640$ & $16,775,214$ & $17,308,400$ & $17,849,055$ & \\
\hline \multicolumn{7}{|c|}{ End date (employment destruction) } \\
\hline Year & $16,467,783$ & $19,821,826$ & $21,678,496$ & $23,652,636$ & $25,453,723$ & $18,070,484$ \\
\hline Month & $1,629,321$ & $1,651,819$ & $1,806,541$ & $1,971,053$ & $2,121,144$ & $2,247,442$ \\
\hline Day & 79,172 & 78,971 & 86,369 & 94,234 & 101,007 & 105,872 \\
\hline Affiliations & $16,442,681$ & $16,357,640$ & $16,775,214$ & $17,308,400$ & $17,849,055$ & \\
\hline
\end{tabular}

Table 7 Job creation and destruction, weekly

\begin{tabular}{|c|c|c|c|c|c|c|}
\hline & 2012 & 2013 & 2014 & 2015 & 2016 & 2017 \\
\hline \multicolumn{7}{|c|}{ Employment creation } \\
\hline Monday & 152,326 & 149,546 & 163,579 & 180,316 & 194,709 & 213,230 \\
\hline Tuesday & 59,102 & 64,878 & 74,893 & 80,931 & 86,707 & 88,360 \\
\hline Wednesday & 61,080 & 58,906 & 63,829 & 75,435 & 76,657 & 81,803 \\
\hline Thursday & 55,177 & 59,752 & 63,085 & 70,611 & 77,402 & 74,532 \\
\hline Friday & 60,073 & 59,246 & 73,463 & 73,336 & 79,576 & 75,601 \\
\hline \multicolumn{7}{|c|}{ Employment destruction } \\
\hline Monday & 127,214 & 127,138 & 139,246 & 157,840 & 179,398 & 186,648 \\
\hline Tuesday & 69,268 & 70,075 & 79,504 & 86,903 & 85,179 & 89,059 \\
\hline Wednesday & 63,294 & 64,718 & 63,797 & 72,307 & 74,418 & 77,214 \\
\hline Thursday & 62,612 & 61,433 & 66,766 & 64,530 & 71,889 & 76,028 \\
\hline Friday & 72,843 & 69,375 & 82,413 & 88,484 & 92,748 & 100,966 \\
\hline \multicolumn{7}{|c|}{ Net employment creation } \\
\hline Monday & 25,112 & 22,408 & 24,333 & 22,476 & 15,311 & 26,583 \\
\hline Tuesday & $-10,166$ & -5197 & -4611 & -5973 & 1529 & -700 \\
\hline Wednesday & -2214 & -5812 & 32 & 3128 & 2239 & 4589 \\
\hline Thursday & -7434 & -1681 & -3681 & 6081 & 5513 & -1496 \\
\hline Friday & $-12,769$ & $-10,130$ & -8950 & $-15,148$ & $-13,171$ & $-25,365$ \\
\hline
\end{tabular}


Table 8 Calendar effect for either the beginning or end of a month

\begin{tabular}{lll}
\hline Monday (first day of the month) & Creation & Destruction \\
\hline 1st Oct, 2012 & 312,747 & 296,082 \\
1st Apr, 2013 & 211,490 & 191,028 \\
1st Jul, 2013 & 387,714 & 333,288 \\
1st Sep, 2014 & 350,770 & 345,255 \\
1st Dec, 2014 & 254,673 & 211,969 \\
1st Jun, 2015 & 308,349 & 292,334 \\
1st Feb, 2016 & 264,599 & 259,412 \\
1st Aug, 2016 & 306,325 & 362,682 \\
\hline Friday (last day of the month) & Creation & Destruction \\
\hline 31 Aug, 2012 & 36,463 & 231,433 \\
30 Nov, 2012 & 41,089 & 145,718 \\
31 May, 2013 & 46,128 & 155,691 \\
31 Jan, 2014 & 37,067 & 130,630 \\
28 Feb, 2014 & 41,673 & 118,445 \\
31 Oct, 2014 & 53,982 & 179,482 \\
31 Jul, 2015 & 49,709 & 245,511 \\
30 Sep, 2016 & 70,357 & 288,176 \\
31 Mar, 2017 & 63,025 & 214,028 \\
30 Jun, 2017 & 84,320 & 341,334 \\
\hline
\end{tabular}

\section{B Contracts data}

Contracts records The daily data on the composition of new contracts correspond to the universe of registers at SISPE (Sistema de Información de los Servicios Públicos de Empleo/Official Register of Employment) of SEPE (Servicio Público de Empleo Estatal/Official Employment Information Administration) from the Spanish Ministry of Employment and Social Security. The sample of contracts goes from January 2011 to August 2017. This implies the use of about 100 million new contracts registered over the period. We restrict to "contract creation" because we only have information on the starting dates of contracts (Fig. 10). All contracts are registered at SISPE with an identifier of the different occupations. The classification of occupations follows roughly the International Standard Classification of Occupations (ISCO-88). To make comparable the data on registered contracts with the aggregate Social Security data of employment spells we are using, we have assigned the contracts registered during the weekends or bank holidays to the closer subsequent labour weekday (Table 9). 
Table 9 New contracts at SEPE, by sector

\begin{tabular}{llllllll}
\hline & $2012(\%)$ & $2013(\%)$ & $2014(\%)$ & $2015(\%)$ & $2016(\%)$ & $2017(\%)$ \\
\hline C21 & Health & 1.70 & 1.81 & 1.78 & 1.80 & 1.78 & 1.73 \\
C22 & Educational & 1.02 & 0.95 & 0.90 & 0.87 & 0.86 & 0.57 \\
C29 & Artistic, literary and cultural & 1.79 & 1.83 & 1.84 & 1.87 & 1.93 & 1.93 \\
C37 & Cultural and sport services & 2.90 & 2.88 & 2.88 & 3.02 & 3.15 & 3.01 \\
C44 & Leisure services & 2.05 & 1.97 & 1.90 & 1.95 & 1.94 & 1.95 \\
C51 & Restaurant services & 12.78 & 12.95 & 13.32 & 13.67 & 14.26 & 14.43 \\
C52 & Shop assistants & 5.32 & 4.91 & 4.88 & 4.85 & 4.80 & 4.70 \\
C54 & Sellers out of shops & 1.87 & 1.71 & 1.68 & 1.61 & 1.62 & 1.49 \\
C56 & Caring & 2.31 & 2.25 & 2.25 & 2.26 & 2.29 & 2.20 \\
C58 & Personal services & 2.41 & 2.21 & 2.18 & 2.16 & 2.24 & 2.17 \\
C71 & Construction skilled & 3.43 & 3.32 & 3.18 & 3.14 & 2.91 & 3.04 \\
C84 & Urban and road transport drivers & 2.51 & 2.55 & 2.57 & 2.60 & 2.63 & 2.69 \\
C91 & Domestic cleaning & 0.90 & 1.42 & 1.25 & 1.15 & 1.06 & 0.98 \\
C92 & Market cleaning & 7.70 & 7.16 & 6.88 & 6.86 & 6.84 & 6.71 \\
C93 & Food preparation & 1.62 & 1.72 & 1.87 & 2.00 & 2.17 & 2.26 \\
C94 & Services elementary & 2.44 & 2.37 & 2.26 & 2.24 & 2.12 & 2.13 \\
C95 & Agricultural elementary & 13.96 & 15.07 & 15.11 & 13.79 & 13.32 & 13.25 \\
C96 & Construction elementary & 2.02 & 2.21 & 2.03 & 2.01 & 1.77 & 1.81 \\
C97 & Manufacturing elementary & 5.15 & 5.33 & 6.00 & 6.54 & 6.95 & 7.41 \\
C98 & Shelf filers and storage & 2.70 & 2.58 & 2.60 & 2.76 & 2.87 & 2.83 \\
\hline
\end{tabular}




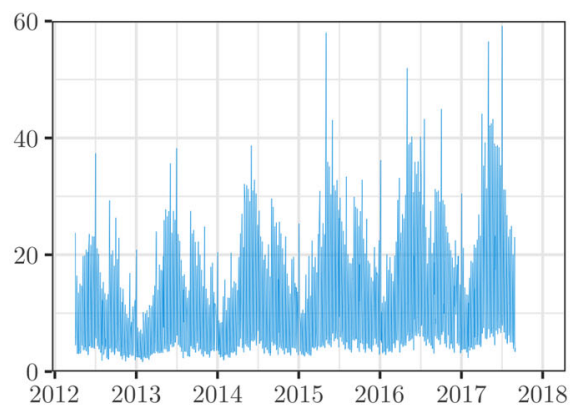

(a) Restaurant Services, C51

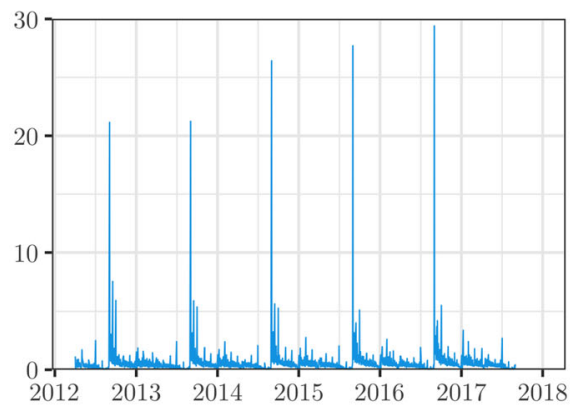

(c) Educational, $\mathrm{C} 22$

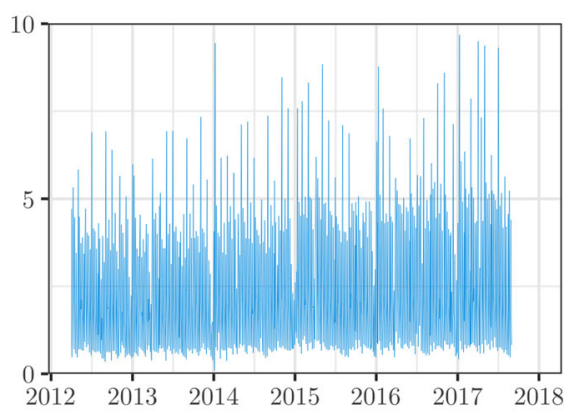

(e) Construction skilled, C71

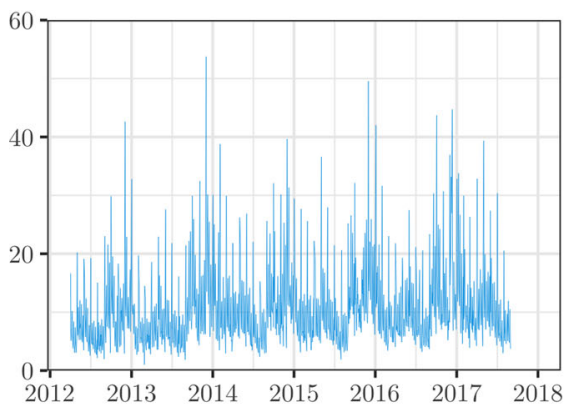

(b) Agricultural elementary, C95

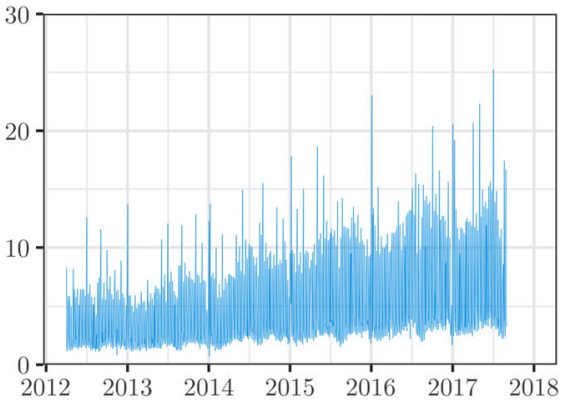

(d) Manufacturing elementary, $\mathrm{C} 97$

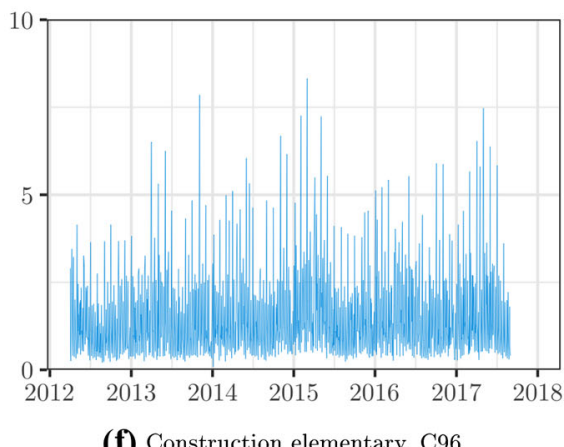

(f) Construction elementary, C96

Fig. 10 Daily contracts in selected sectors according to SEPE (note scale from top to bottom in thousands: $60,000,30,000,10,000)$

\section{References}

Amuedo-Dorantes C (2000) Work transitions into and out of involuntary temporary employment in a segmented market: evidence from Spain. Int Labor Relat Rev 53(2):309-325

Arranz JM, García-Serrano C (2014) The interplay of the unemployment compensation system, fixed-term contracts and rehirings: the case of Spain. Int J Manpow 35(8):1236-1259

Benito A, Hernando I (2008) Labour demand, flexible contracts and financial factors: firm-level evidence from Spain. Oxf Bull Econ Stat 70(3):283-301 
Bentolila S, Dolado J, Jimeno JF (2008) Two-tier employment protection reforms: the Spanish experience. CESifo DICE Report 4/2008 2008, pp. 49-56

Bentolila S, Dolado J, Jimeno JF (2012) Reforming an insider-outsider labor market: the Spanish experience. IZA J Eur Labor Stud 1:4

Bentolila S, García Pérez JI, Jansen M (2017) Are the Spanish long-term unemployed unemployable? SERIEs 8(1):1-41

Berument H, Kiymaz H (2001) The day of the week effect on stock market volatility. J Econ Financ 25(2):181-193

Blanchard O, Tirole J (2003) Contours of employment protection reform. MIT Department of Economics working paper \#03-35

Blanchard O (2004) Reforming labor market institutions: unemployment insurance and employment protection. MIT Department of Economics working paper \#04-38

Bonhomme S, Hospido L (2017) The cycle of earnings inequality: evidence from Spanish social security data. Econ J 127(603):1244-78

Caballero R, Engel E, Haltiwanger J (1997) Aggregate employment dynamics: building from microeconomic evidence. Am Econ Rev 87(1):115-137

Cahuc P, Nevoux S (2018) Inefficient short-time work. Working paper \#693, Banque de France

Camacho M, Pacce M, Ulloa C (2017) Business cycle phases in Spain. Working paper \#17-20, BBVA Research

Carrasco R (1999) Transitions to and from self-employment in Spain: an empirical analysis. Oxf Bull Econ Stat 61(3):315-341

Conde-Ruiz JI, García M, Puch LA, Ruiz J (2018) "Calendar Effects in Daily Aggregate Employment Creation and Destruction in Spain," Studies on the Spanish Economy 18-04

Costain J, Jimeno JF, Thomas C (2010) Employment fluctuations in a dual labor market. Banco de España working paper \#10-13

Del Bono E, Weber A (2008) Do wages compensate for anticipated working time restrictions? Evidence from seasonal employment in Austria. J Labor Econ 26(1):181-221

Dolado J, García-Serrano C, Jimeno JF (2002) Drawing lessons from the boom of temporary jobs in Spain. Econ J 112(480):270-295

Felgueroso F, García-Pérez JI, Jansen M, Troncoso-Ponce D (2017) Recent trends in the use of temporary contracts in Spain, Mimeo, September

García-Pérez JI, Muñoz-Bullón F (2011) Transitions into permanent employment in Spain: an empirical analysis for young workers. Br J Ind Relat 49(1):103-43

García-Pérez JI, Mestres-Domènech J (2017) The impact of the 2012 Spanish labour market reform on unemployment inflows and outflows: a regression discontinuity analysis using duration models. Working papers \#17-02, Universidad Pablo de Olavide

Güell M, Petrongolo B (2007) How binding are legal limits? Transitions from temporary to permanent work in Spain. Labour Econ 14(2):153-183

Izquierdo M, Lacuesta A, Puente S (2013) The 2012 labour reform: an initial analysis of some of its effects on the labour market. Economic Bulletin September, Bank of Spain

Nagore A, van Soest A (2017) Unemployment exits before and during the crisis. Labour 31(4):337-368

Soares-Esteves P, Rodrigues P (2010) Calendar effects in daily ATM withdrawals. Working paper \#2010-12, Banco de Portugal

Verbaan R, Bolt W, van der Cruijsen C (2017) Using debit card payments data for nowcasting Dutch household consumption. DNB working paper \# 571

Wolfers J (2005) Employment protection and job flows: evidence from seasonal cycles, Mimeo

Publisher's Note Springer Nature remains neutral with regard to jurisdictional claims in published maps and institutional affiliations. 


\section{Affiliations}

\section{J. Ignacio Conde-Ruiz'1,2 Manu García ${ }^{1,2}$ - Luis A. Puch ${ }^{2,3}$ - Jesús Ruiz ${ }^{2,3}$}

$\triangle$ Luis A. Puch

lpuch@ccee.ucm.es

J. Ignacio Conde-Ruiz

nacho.conderuiz@gmail.com

Manu García

manutzn@gmail.com

Jesús Ruiz

jruizand@ccee.ucm.es

1 Fedea, Madrid, Spain

2 Department of Economic Analysis, Universidad Complutense de Madrid, Madrid, Spain

3 ICAE, Universidad Complutense de Madrid, Madrid, Spain 